NISTIR 7944

\title{
Fingerprint Scanner Affordances
}

Michelle Steves

Brian Stanton

Mary Theofanos

Dana Chisnell

Hannah Wald 
NISTIR 7944

\title{
Fingerprint Scanner Affordances
}

\author{
Michelle Steves \\ Brian Stanton \\ Mary Theofanos \\ Information Access Division \\ Information Technology Laboratory \\ Dana Chisnell \\ Usability Works \\ Boston, MA \\ Hannah Wald \\ Booz Allen Hamilton \\ McLean, VA
}

http://dx.doi.org/10.6028/NIST.IR.7944

September 2013

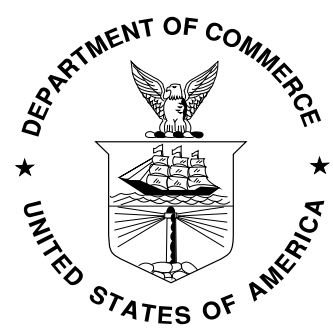

U.S. Department of Commerce Rebecca Blank, Acting Secretary

National Institute of Standards and Technology Patrick D. Gallagher, Under Secretary of Commerce for Standards and Technology and Director 


\section{TABLE OF CONTENTS}

1 INTRODUCTION

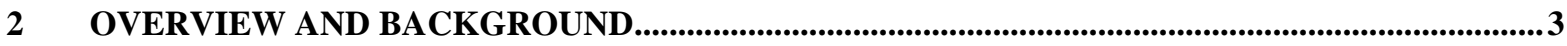

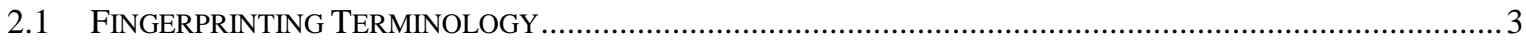

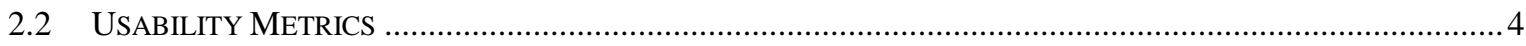

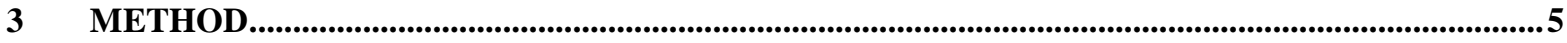

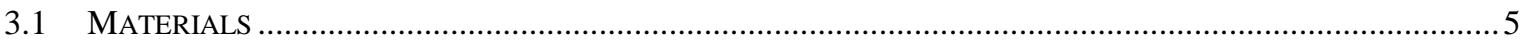

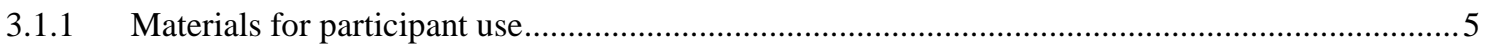

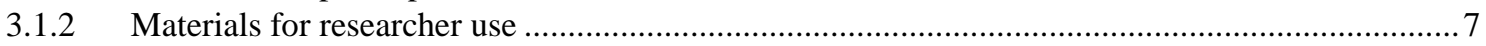

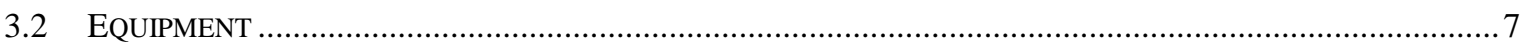

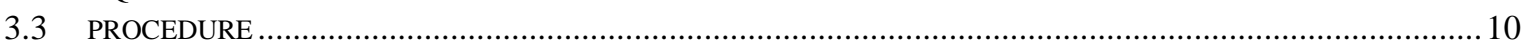

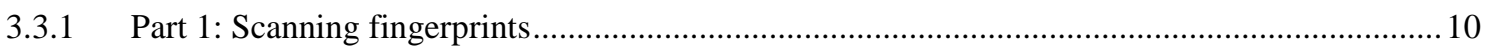

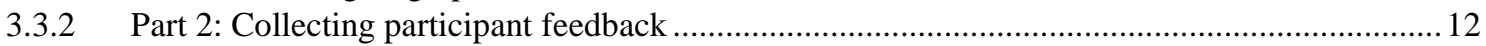

3.3.3 Part 3: Post-processing of the collected images ......................................................................... 13

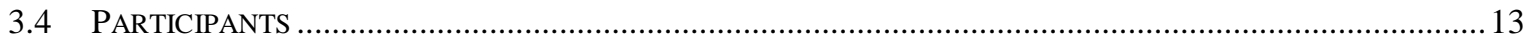

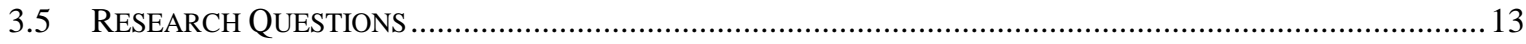

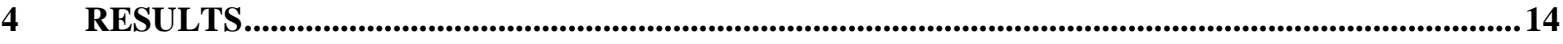

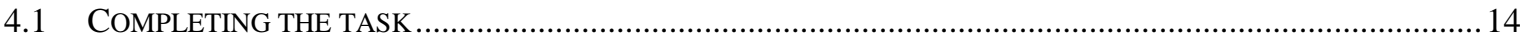

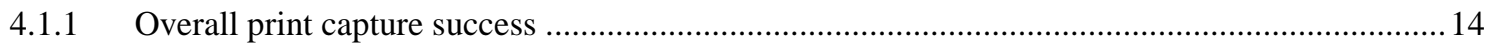

4.1.2 The capture process - researcher observations ............................................................................ 15

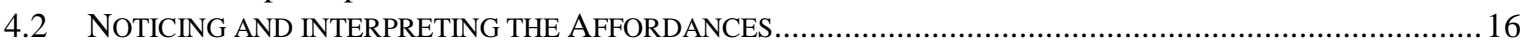

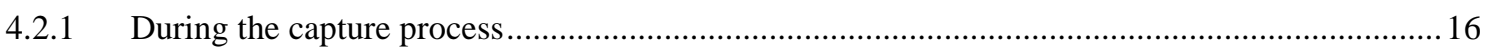

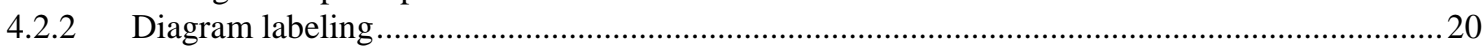

4.2.3 What guided participants as they used the scanner - self-reported ..........................................2

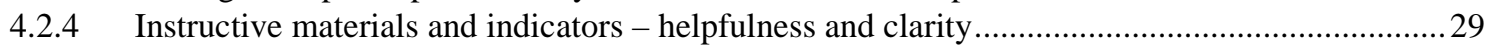

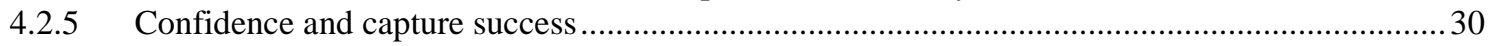

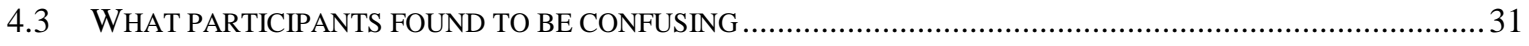

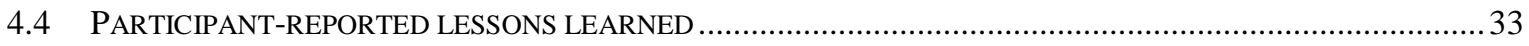

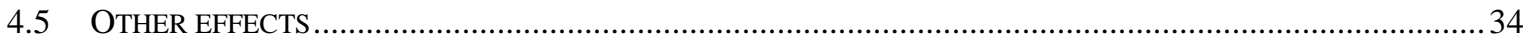

4.5.1 Effects of subject demographics on capture success .................................................................... 34

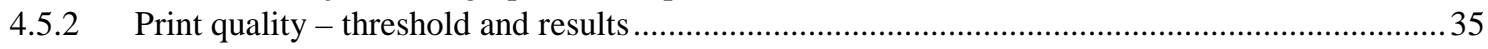

4.5.3 Number of attempts to make a successful slap.............................................................................. 36

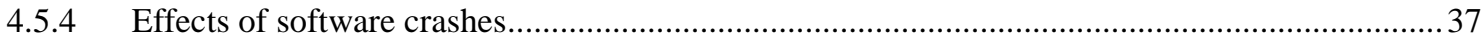

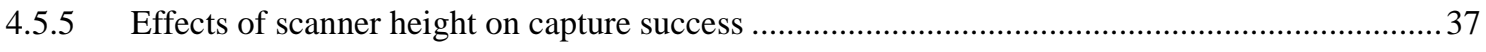

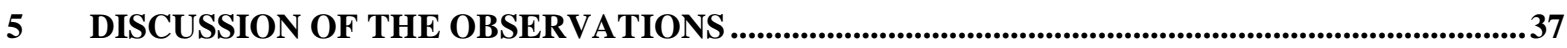

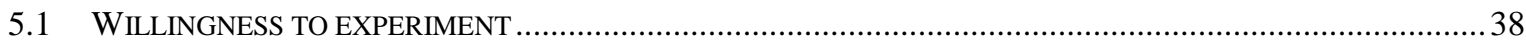

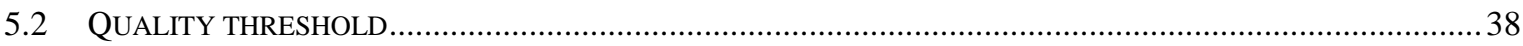

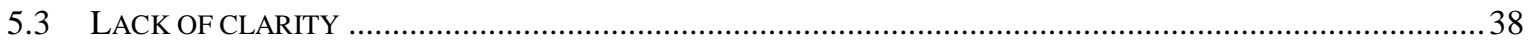

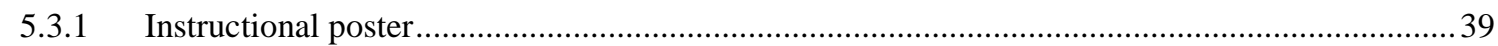

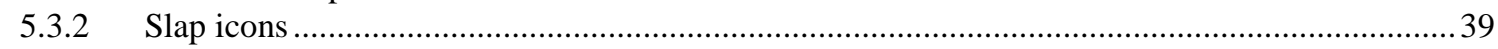

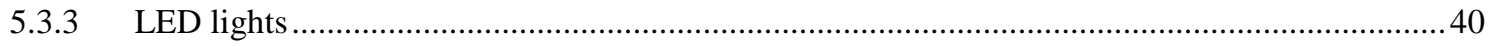




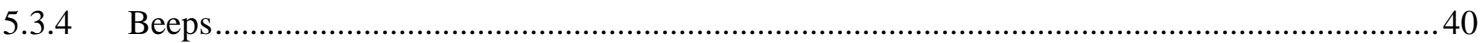

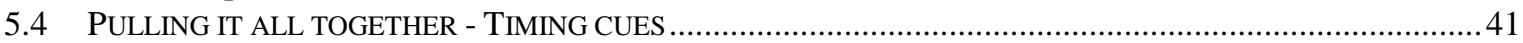

5.5 OVERALL SUITABILITY OF SCANNER FOR SELF-SERVICE USE .......................................................41

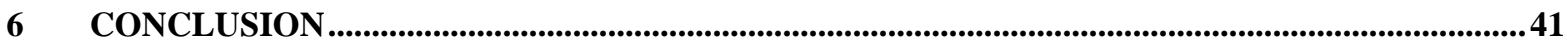

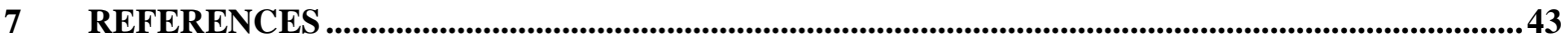

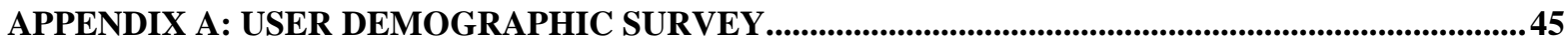

APPENDIX B: FINGERPRINT SCANNER DATASHEET .....................................................................47

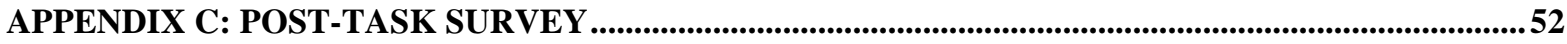




\section{LIST OF TABLES AND FIGURES}

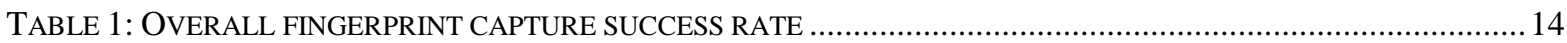

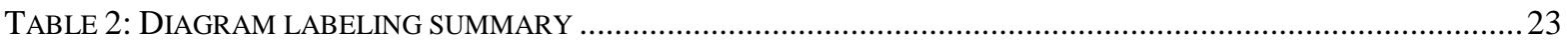

TABLE 3: INSTRUCTIONAL INDICATORS USED BY PARTICIPANTS AND CAPTURE SUCCESS ......................................28

TABLE 4: PARTICIPANT RELIANCE ON INSTRUCTIONAL POSTER AND CAPTURE SUCCESS........................................ 28

TABLE 5: PARTICIPANTS' RATINGS OF THE CLARITY AND HELPFULNESS OF THE US-VISIT POSTER ......................29

TABLE 6: PARTICIPANTS' RATINGS OF THEIR CLARITY ON ASPECTS OF THE FINGERPRINT PROCESS.........................30

TABLE 7: PARTICIPANT CONFIDENCE SCORES AND CAPTURE SUCCESS (MEAN \pm SE) …....................................... 30

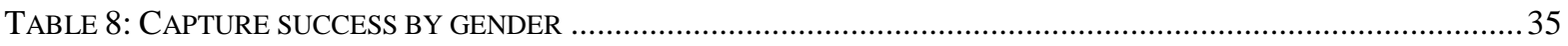

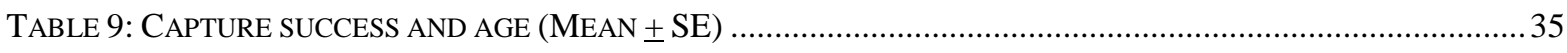

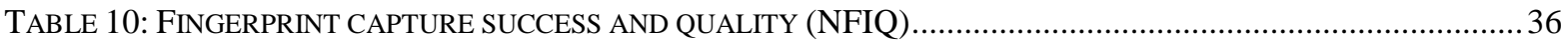

TABLE 11: AVERAGE NUMBER OF SLAP ATTEMPTS AND CAPTURE SUCCESS......................................................... 36

FIGURE 1: INSTRUCTIONAL US-VISIT POSTER PROVIDING THE BIOMETRIC DATA CAPTURE PROCESS ..................... 6

FIGURE 2: DIAGRAM OF SCANNER THAT PARTICIPANTS ANNOTATED...........................................................

FIGURE 3: FINGERPRINT SCANNER WITH INDICATORS ................................................................................... 8

FIGURE 4: SCREEN IMAGE SHOWING POSITIONING OF A RIGHT SLAP ON THE PLATEN ...........................................

FIGURE 5: SCREEN IMAGE SHOWING A COMPLETE SET OF PRINTS AS CAPTURED AND STORED ............................... 9

FIGURE 6: AN EXAMPLE OF A PARTICIPANT'S SCANNER DIAGRAM WHERE MOST FEATURES ARE LABELED

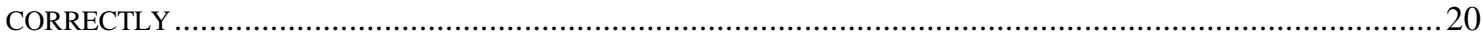

FIGURE 7: AN EXAMPLE OF A PARTICIPANT'S SCANNER DIAGRAM WHERE ONLY SOME FEATURES ARE LABELED

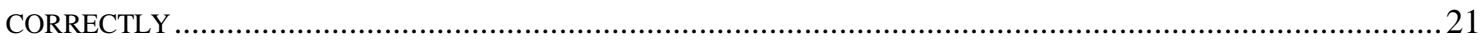

FIGURE 8: AN EXAMPLE OF A PARTICIPANT'S SCANNER DIAGRAM WITH MINIMAL LABELING ............................22 


\section{EXECUTIVE SUMMARY}

Under the United States Visitor and Immigrant Status Indicator Technology (US-VISIT) program, the Department of Homeland Security (DHS) collects biometric information from foreign nationals entering the country. Foreign nationals are required to - among other things - undergo a ten-fingerprint scanning process, which is conducted by a customs agent. This scan is only performed upon entry into the United States. DHS is investigating the feasibility of deploying an unassisted "self-service" fingerprint scanning solution as well for when foreign nationals exit the country.

To that end, DHS requested assistance from NIST to examine the affordances of the fingerprint scanner when used with the US-VISIT instructional poster, both of which were in use at U.S. ports of entry when this study was conducted (Feb-Mar 2010), to learn how travelers interpret these features. For example, whether they help travelers use the scanner in such a way that the scanner can capture clear pictures of travelers' prints, and whether a person can present a usable fingerprint sample to the scanner without assistance. Findings from this study will inform future efforts to design a self-service fingerprint solution that can be effectively used by the vast majority of people regardless of age, nationality, or level of technical proficiency.

In this study, 62 participants used the same instructional poster and fingerprint scanner employed by the US-VISIT program and underwent the same process employed in that program, except that they did not receive any guidance from the person operating the fingerprint scanner. We observed their behavior during the process, evaluated how well they completed the fingerprinting task, i.e., whether they got the scanner to take a clear picture of some or all of their fingerprints, and afterwards we asked them questions about their experience using the scanner.

Our findings indicate that the US-VISIT poster and scanner, as implemented, will not constitute a workable self-service fingerprinting solution. The US-VISIT poster provided our study participants with a general idea of what to do, but left them unsure of specifics such as how long to hold their fingers on the platen or how to tell whether the scanner had managed to get a clear image of their fingerprints - a finding consistent with a previous study involving a similar instructional poster [11]. The affordances on the scanner itself, consisting of instructional icons and light emitting diodes (LEDs), are designed to provide this information; however, many participants either failed to notice or misinterpreted them.

Users will need additional support in the form of more detailed instructional material, feedback from the scanner, or both. Any self-service solution needs to clearly communicate 
what is expected of the user and indicate whether the user is or is not meeting those expectations.

\section{INTRODUCTION}

The National Institute of Standards and Technology (NIST) has conducted a series of studies focusing on the usability and human factors elements that affect the capture of fingerprint and facial images for the United States Visitor and Immigrant Status Indicator Technology (US-VISIT) program. In one study, NIST evaluated the effectiveness of a face overlay guide in helping operators center subjects' faces when capturing a facial image [7]. A subsequent study examined how instructional materials could be used to guide travelers through a 10print collection process [11]. These tests were funded by DHS.

Both studies examined the effectiveness of affordances in or on the devices being tested. An affordance, as originally defined by J.J. Gibson in the late 1970s, refers to the "actionable properties between the world and an actor (a person or animal)." As Donald Norman points out, in design, "What the designer cares about is whether the user perceives that some action is possible" (emphasis added) [3]. We would add that the user must perceive that the action we want them to take is possible and desirable as a step in reaching a goal. The results of the NIST studies indicated that there is still work to be done to identify characteristics that improve affordances and, in turn, the performance of travelers during biometric data collection processes.

A key part of the US-VISIT apparatus is the fingerprint scanner. Studies show that women and older adults typically need many more tries than younger males do to use the fingerprint scanner to obtain usable images of their prints [8]. In the current setup, which is only for entering the country, a Customs and Border Protection officer guides travelers through this process. Work performed prior to the study suggested that many people would not be able to use the scanner successfully without assistance. NIST's prior research in this area found that, while instructional materials helped people in the study to provide clear, usable fingerprints, the form of the instructional materials affected the process [11].

This study examined the light emitting diode (LED) indicators and instructional icons on the fingerprint scanner type ${ }^{1}$ in place in U.S. ports of entry (at the time of the study) to learn if

1 The use of certain commercial equipment in this study is not intended to imply recommendation or endorsement by National Institute of Standards and Technology, nor is it intended to imply that the equipment shown is necessarily the best available for the purpose. 
people interpret these features as intended, are guided through the fingerprint collection process, and whether they can present usable fingerprint samples to the scanner without assistance. The results from this study will be used to inform the development of a "selfservice” fingerprinting solution.

\section{OVERVIEW AND BACKGROUND}

The study described in this report investigated whether users can accomplish the following without assistance: 1 ) determine the order and positioning of hands and fingers on the fingerprint scanner's platen by looking at the lights on the scanner and using the instructional diagrams in the US-VISIT poster, and 2) by doing so, produce quality fingerprint images. The results and recommendations from this study will inform decisions feeding into the design of a US-VISIT “self-service” fingerprint scanning device.

\subsection{FINGERPRINTING TERMINOLOGY}

In this study, we frequently use the following terms associated with the fingerprint scanning process: [5]

- User - This is the person whose fingerprints are being scanned, rather than the system operator. The participants in this study are users.

- Presentation - The display of biometric characteristics to a sensor. In this case, a user presents his/her fingerprints by placing his/her finger(s) on the platen of a scanner.

- Capture - The collection of data on biometric characteristics presented by a user. In this case, a fingerprint scanner captures a digital image of a user's fingerprint(s).

- Slap - The specific term for presentation of fingers to the fingerprint scanner. The US-VISIT fingerprint collection involves a sequence of four slaps: the four fingers of the right hand, without thumb (right four-finger slap); the right thumb; the four fingers of the left hand (left four-finger slap); and the left thumb.

For purposes of this study, a successful presentation means a slap from which the fingerprint scanning system was able to capture an image. Typically, an unsuccessful presentation means one of the following: 1) the system was unable to capture anything, 2) an incomplete set of fingers (relative to what was presented) was captured for a right or left finger slap, or 3) a finger or slap was captured that differed from the slap expected by the scanner. Additionally, for the purposes of this study, our procedure was to accept any print the scanner attempted to 
collect, regardless of order. An incomplete set of successful presentations is another type of failure.

\subsection{USABILITY METRICS}

A self-service fingerprint scanner must possess a critical general property: usability. The definition of usability, according to ISO 9241-11, [1] is "the extent to which a product can be used by specified user to achieve specified goals with effectiveness, efficiency and satisfaction in a specified context of use." The assumption inherent in this definition is that the measures are applied in an evaluation of a finished design.

In the case of this study, however, the measures were applied in an exploratory fashion to examine the behavior and perceptions of users. Because this study was exploratory, we employed different metrics from those used for summative tests. We wanted to learn whether people noticed the affordances on the fingerprint scanner, e.g., lights, icons and audible tones as identified in Section 3.2, and if they did, whether they understood the affordances, and if the affordances helped them present their fingerprints in such a way that the scanner was able to successfully capture images of acceptable quality, i.e., a NIST Fingerprint Quality [NFIQ] score of $1-3$, indicating the quality assessment to be a level that is an excellent (1) to good (3) predictor of a fingerprint matcher's performance [6].

Again, due to the exploratory nature of the study, efficiency metrics were not part of the scope of this study. For example, though we were aware of the time it took participants to scan their fingerprints, we did not measure performance against time on the task. At this early stage, we were more interested in whether people were able to use the scanner successfully while unassisted - whether they were effective in providing fingerprint images at all, and whether those prints were of sufficient quality.

Additionally, we were interested in the study participants' perceptions of the scanner and the process of using it. We wanted to know whether participants were confident in their ability to use the scanner to capture prints without assistance and to compare participants' confidence levels with their success in capturing usable prints. We were also interested in knowing their impressions of what guided them through the process and the clarity of that guidance rather than their overall user satisfaction.

If participants were both confident and successful in providing usable fingerprint samples, the design of this scanner could be considered viable for a self-service fingerprint capture device. If participants were successful but not confident, we would be able to make inferences about what users would need to perceive progress and completion. If participants were not successful but were confident, this might indicate serious flaws with the scanner's 
affordances; and, we would gain insights on how to set appropriate expectations in the design of the self-service device.

\section{METHOD}

In this study, we focused on users undergoing an unassisted fingerprint capture process using the fingerprint scanner type in use at U.S. ports of entry. In the test scenario, users had some written instruction via the US-VISIT poster, shown in Figure 1, page 6, on how to go through the process, but no human assistance. Our objectives were twofold: first, we wanted to investigate the perceptions of users undergoing the process, and second, we wanted to assess participants' effectiveness in the test scenario.

\subsection{MATERIALS}

The materials used by participants and researchers in the study are listed below.

\subsubsection{Materials for participant use}

- Fingerprint scanner

- Informed consent form explaining the study and how the data would be used

- Demographic questionnaire asking about ethnicity, occupation, handedness, and experience with biometric data collection, contained in Appendix A: User Demographic Survey

- $45.7 \mathrm{~cm}$ by $58.4 \mathrm{~cm}$ (18 in x 23 in) US-VISIT poster displayed on the wall in front of the participant with basic instructions describing how to present fingerprints for capture, depicted in Figure 1 


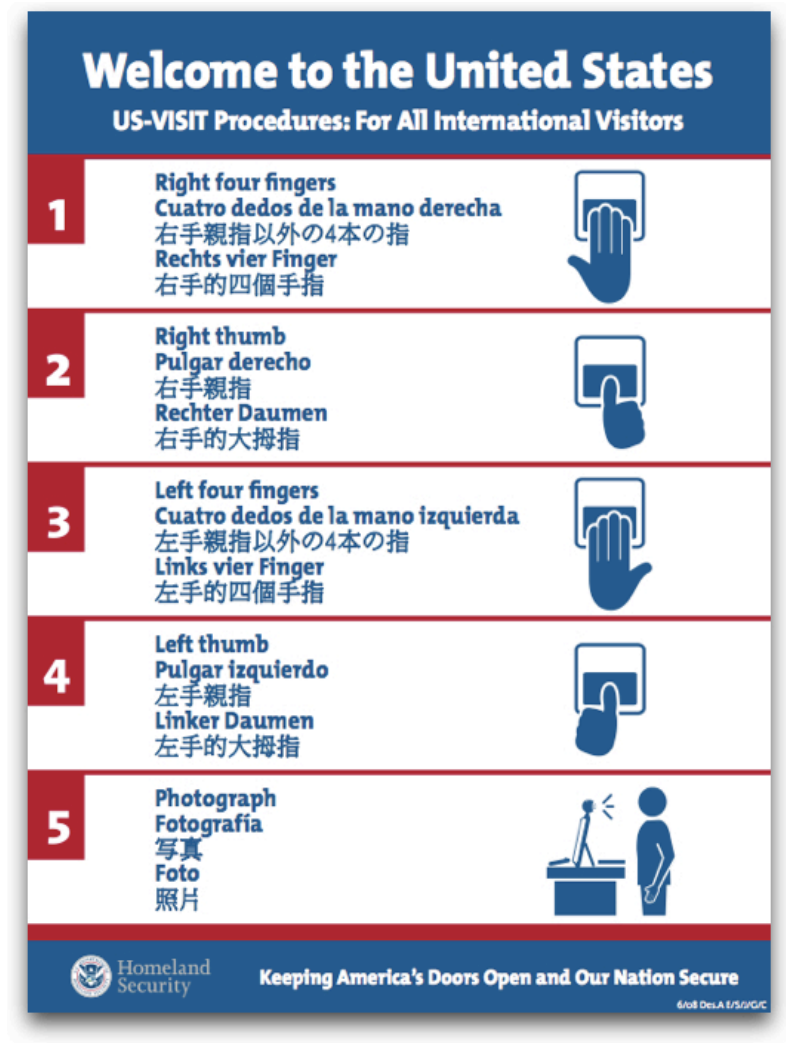

Figure 1: Instructional US-VISIT poster providing the biometric data capture process

- Unlabeled diagram of the fingerprint scanner used by the participant to draw any features they noticed on the device, as shown in Figure 2. The diagram of scanner that participants annotated measured approximately $16.0 \mathrm{~cm}$ by $15.2 \mathrm{~cm}$, whereas the scanner measured $15.2 \mathrm{~cm}$ by $15.2 \mathrm{~cm}$. 


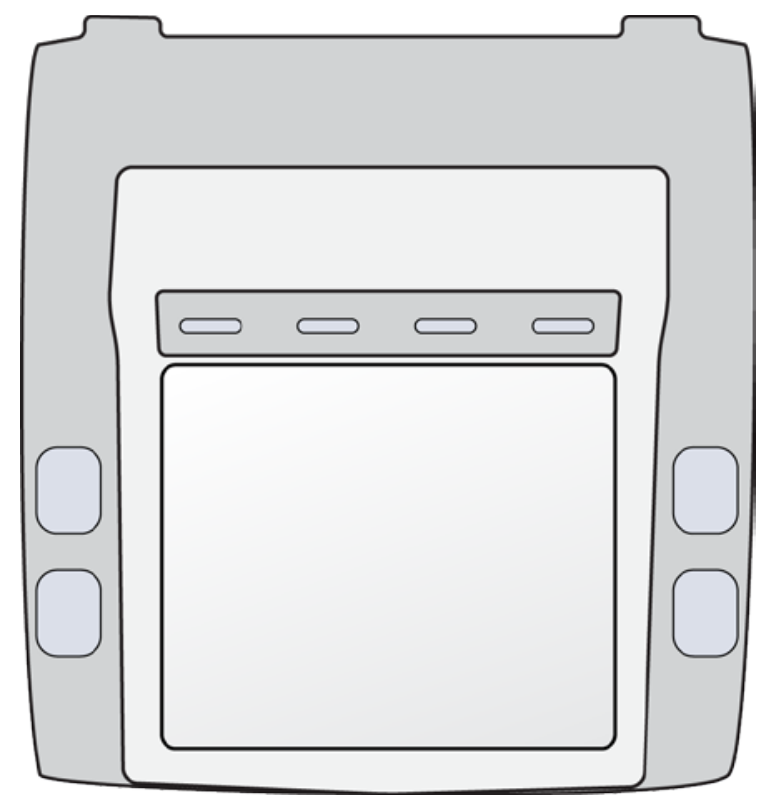

Figure 2: Diagram of scanner that participants annotated

- Post-task questionnaire that asked participants questions about their experience with the fingerprint scanner, including how confident they were that they had used it correctly, how clear and effective they considered the US-VISIT poster and scanner affordances to be, and whether they had any additional comments on the fingerprinting process. The questionnaire is provided in Appendix C: Post-Task Survey.

\subsubsection{Materials for researcher use}

- Script containing directions on what to say to participants, how to move from station to station in the lab space, and how to collect data

- Data collection sheets for recording observations and participants' comments, provided in Appendix B: Fingerprint Scanner Datasheet

- Vendor-supplied image capture and management software

\subsection{EQUIPMENT}

The fingerprint scanner used in this study - shown in Figure 3 - measured approximately $15.2 \mathrm{~cm}$ ( $6.0 \mathrm{in}$ ) by $15.2 \mathrm{~cm}$ (6.0 in) by $15.2 \mathrm{~cm}$ (6.0 in). There were four LED lights at the 
top edge of the scanner platen surface, each capable of emitting a red or a green light. On each side of the platen were two illuminated indicators (four in total) corresponding to a Right Slap, Right Thumb (on the right side), Left Slap, and Left Thumb (on the left side). The scanner also emitted audible tones - beeps - whenever it successfully captured a print image. Note that what appears to be a horizontal line or delineation between the left and right icons is inside the scanner and not anything present at the surface of the platen.

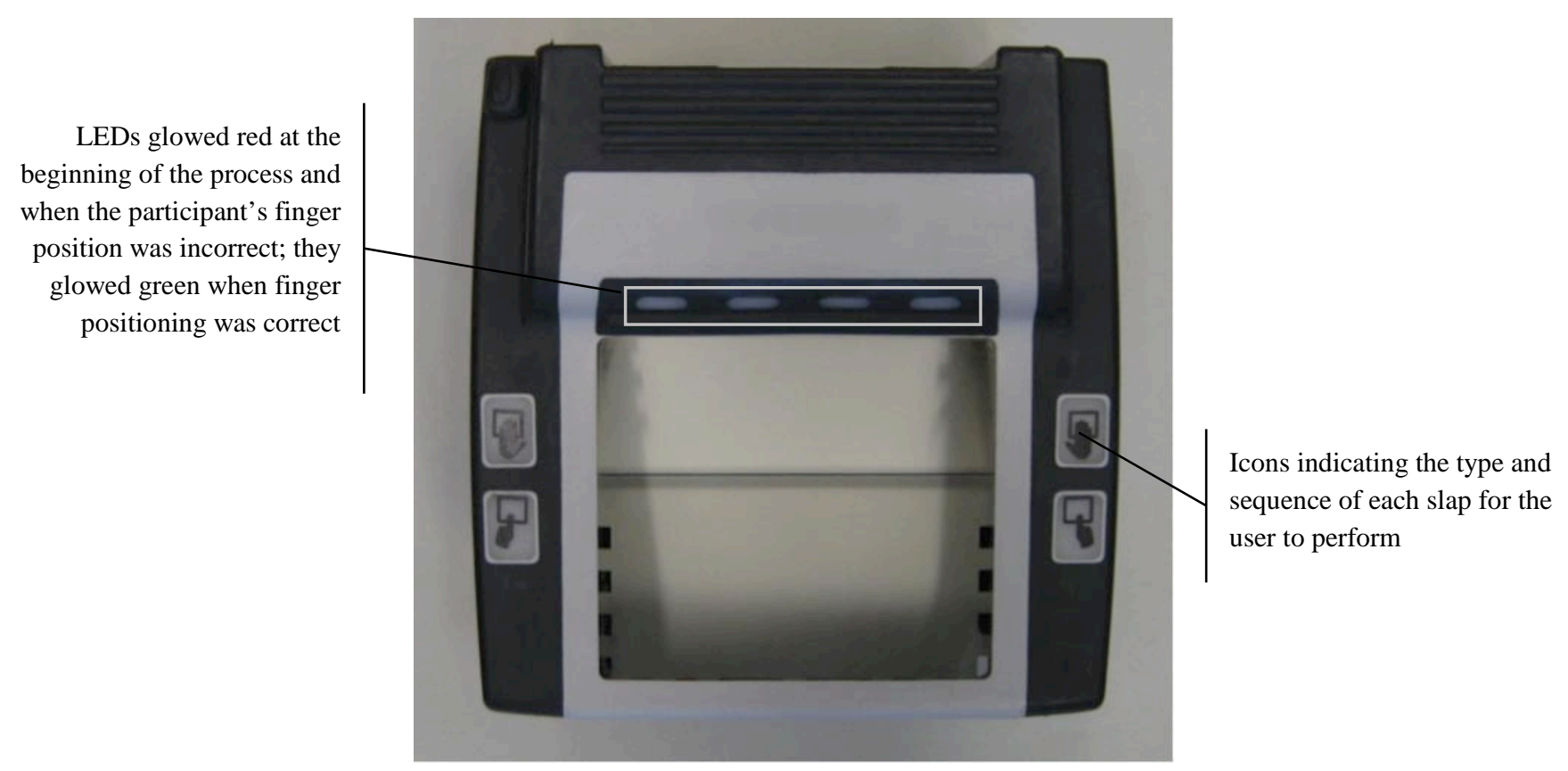

Figure 3: Fingerprint scanner with indicators

To control the fingerprint scanner and collect the digital images of participants' fingerprints, the image capture and management software supplied by the scanner vendor was used. Figure 4 contains an image of the operator's view of an example of a slap image captured using this software. Figure 5 provides an example of a complete set of captured fingerprints the ideal outcome of the fingerprinting task. 


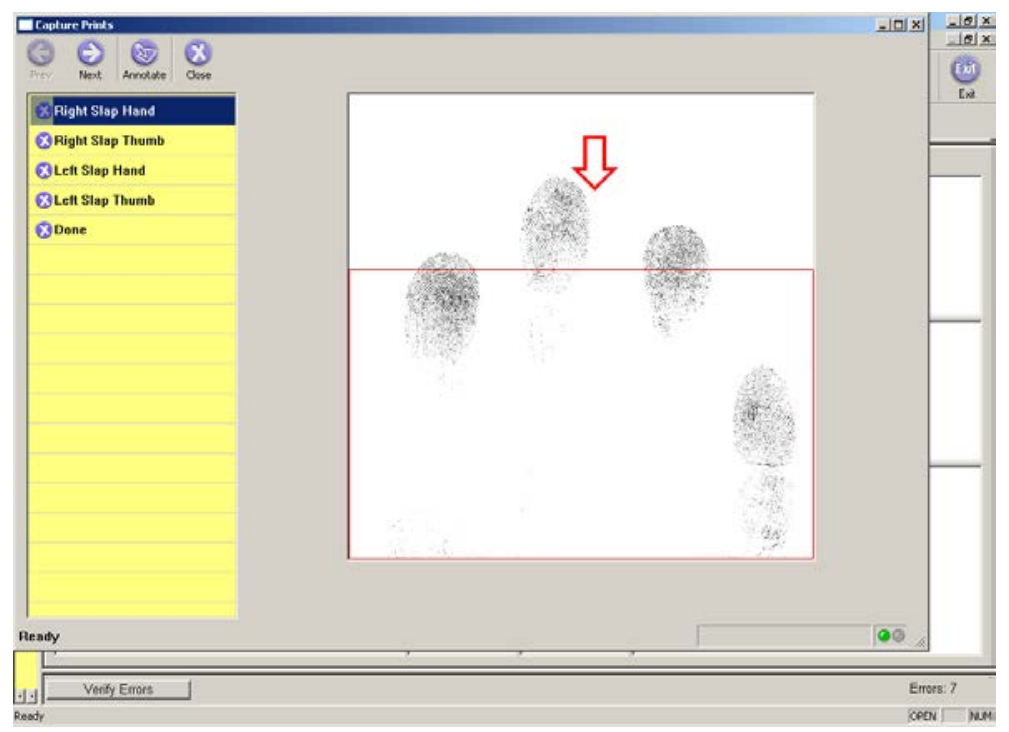

Figure 4: Screen image showing positioning of a right slap on the platen

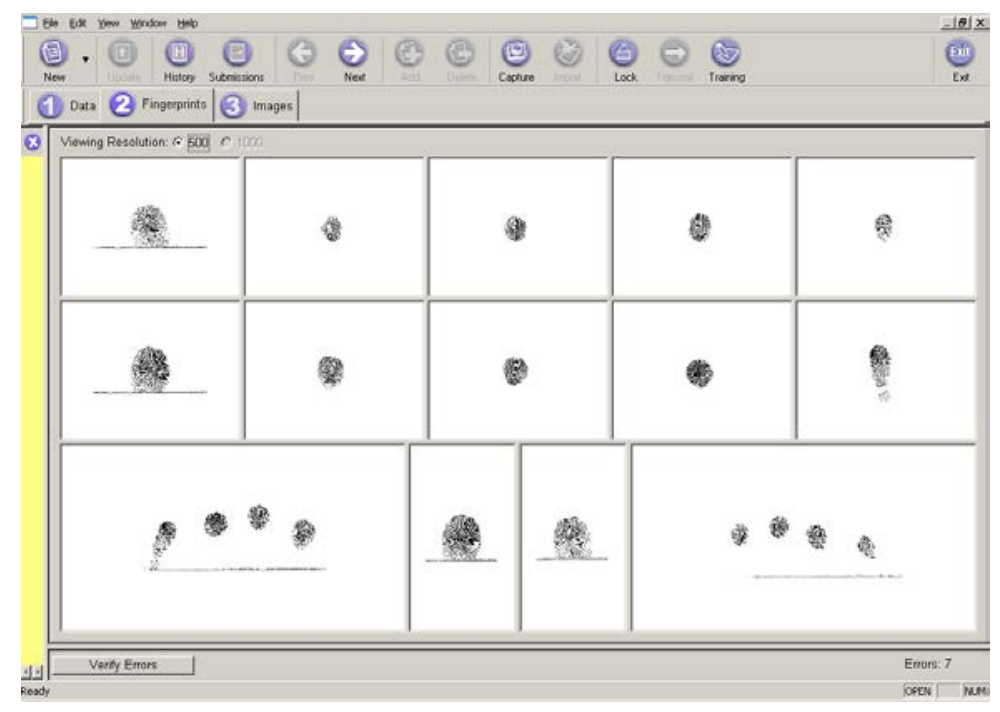

Figure 5: Screen image showing a complete set of prints as captured and stored 


\subsection{PROCEDURE}

After filling out a demographic questionnaire, each participant went through a two-part process. First, the participant used a fingerprint scanner while being observed by, but receiving no assistance from, the researcher. The researcher also operated the fingerprint scanning software, which required only occasional glances at a computer monitor and clicking of the mouse. Second, the participant was asked to provide feedback on his or her experience with the scanner and any related thoughts or impressions. Each of the two parts took roughly 8 to12 min, depending on the participant. As part of the analysis after data collection was completed, the quality of the captured fingerprint images was assessed with the NFIQ algorithm.

\subsubsection{Part 1: Scanning fingerprints}

The researcher explained to each participant that foreign nationals use the fingerprint scanner at major U.S. airports. In addition, the researcher asked participants to verbalize while using the scanner, specifically to talk about what they were doing and their observations during the process.

The researcher did not provide the participants with any assistance or instructions on how to complete the task before or during the process. The only guidance the participants received came from the US-VISIT poster on the wall in front of them and the affordances of the fingerprint scanner itself.

While the participant underwent the scanning process, the researcher took notes on the participant's behavior, recorded any comments the participant made, and responded to occasional prompts from the scanner's operator interface (see Section 3.3.1.3).

\subsubsection{The scanning process}

As shown in Figure 3, the fingerprint scanner had 4 LED lights across the top and 4 slap icons along the sides of the platen. When the scanner was ready, all of the LED lights were red and one of the four indicators on the sides of the platen was illuminated. The sequence in which the indicators were illuminated corresponded to the US-VISIT slap sequence: right four-finger slap, right thumb slap, left four-finger slap, and left thumb slap.

Once the participant placed a thumb or fingers on the platen, the four LED lights indicated whether or not the scanner was able to read the user's fingerprints for the particular slap. When the user performed a right four-finger slap, the corresponding LED lights, e.g., the one on the far left for the index finger, the one on the far right for the little finger, turned from red 
to green if the scanner was able to read the appropriate fingerprints. Once all four lights turned green - indicating that all the fingers were readable - the scanner checked the quality of the fingerprint image it was attempting to capture. After a few seconds (presumably checking the quality), if the quality was acceptable, the scanner captured the image and beeped, indicating that it successfully captured an image. If the quality was insufficient, the scanner would stay on the same slap, until a successful capture or the scanner timed out and moved to the next slap. The process was similar for a thumb slap, except that the only LED illuminated was either the second one from the right (for a right thumb slap) or the second one from the left (for a left thumb slap).

\subsubsection{Fingerprint capture software}

While the fingerprint scanner scanned participants' fingerprints, the LSMS software running on an attached PC displayed the fingerprint images to the researcher. The software rated the image quality using a proprietary measure. Note, that this assessment was employed by the scanner software to set a quality threshold to be met before an image was stored. In the system configuration used in this study, the software would automatically store fingerprint images only if they had a quality score of 3 or better. This quality assessment was different than the use of the NFIQ score for prints that were captured - a metric used to analyze whether the captured fingerprint images were of "good" or better quality after the data gathering portion of the study had concluded (described in 3.3.3).

However, if there were other issues that affected fingerprint image capture - for example, if there appeared to be digits missing from a slap - the system would display a message prompt on the operator's monitor, asking whether it should accept or decline the captured image. These were accepted. Similarly, it was not unusual for slaps to be captured in the wrong order because the first good image was often the right thumb. When the LSMS software detected this, it showed the scanner operator the "accept/decline” message described above. The researcher operating the scanner in this study always chose to "accept" the image.

Note: after the data were collected, we found that in cases where the researcher directed the software to accept a right or left 4-finger slap while the scanner was looking for a thumb, produced a situation where the scanner indicated to the participant that the print had been captured (beep given) however, the software did not store the image. There were six participants who experienced this. Since these participants did not have any other successful prints and these out-of-order prints were not captured, these participants were categorized as having no fingerprints collected, even though they received the beep. 


\subsubsection{Researcher activity during scanning process}

The object of the study design was to simulate as much as possible a scenario in which a user undergoes an automated fingerprint scanning process without any kind of assistance. Therefore, whenever the LSMS software prompted the researcher to accept or decline captured images from a participant's slap, the researcher's default decision was to accept. If there was no capture but the system showed an accept/decline prompt, the scanner operator simply did whatever he/she needed to do to allow the test to move forward. This meant that slaps for some participants were stored in the wrong order, e.g., a right thumb slap when there should have been a right four-fingered slap.

In some cases, a participant would attempt a slap multiple times. In this study, we define an "attempt" or "try" as placing the finger(s) on the platen. So, if a participant lifted his/her fingers to change their position on the platen, the researcher counted that as an attempt, and recorded the number of attempts participants made for each slap.

\subsubsection{Part 2: Collecting participant feedback}

After the participant completed the fingerprint scanning process, the researcher gave him/her a black-and-white line drawing of the surface of the scanner Figure 2. The diagram showed the basic outlined shapes, without color or detail, of the LED lights and slap icons at the edges of the scanner platen. The researcher instructed the participant to draw and label on the diagram any features the participants recalled from the scanner during the fingerprinting process, including what the scanner did. The participants did not have access to the actual scanner or instructional poster during this exercise. Participants often described what they were drawing or writing without prompting from the researcher.

When the participant said he/she was finished drawing on the diagram, the researcher asked the participant to describe what he/she remembered seeing during the scanning process. If the participant did not mention the lights, slap icons, and beeps in his/her description, the researcher asked the participant if he/she remembered them.

Finally, participants completed a post-task questionnaire that asked them about various aspects of their experience with the scanner, such as whether they thought the US-VISIT poster provided them with helpful instructions on how to use the scanner, whether the lights on the scanner itself were useful indicators, and how confident participants were that they had used the scanner correctly. Appendix C: Post-Task Survey contains the entire questionnaire. 


\subsubsection{Post-processing of the collected images}

After the data collection phase was complete, assessment of the print quality was performed in the following manner: for the prints that were captured, the NFIQ value was computed as an assessment of quality. The NFIQ scores were obtained for individual prints by taking each image stored by the scanner for each participant, which was a digital image of a set of fingerprints, arranged similarly to that of an inked fingerprint card. That image was segmented into a set of individual images, one for each fingerprint captured. Images of individual prints were assessed with the NFIQ algorithm [6], using the NIST software that implements the NFIQ algorithm [3].

\subsection{PARTICIPANTS}

A total of 62 participants used the fingerprint scanner in this study. 30 were men and 32 were women. The average age was 38 years, with participants ranging in age from 20 to 66 years.

We measured the height of each participant to counterbalance two heights for the fingerprint scanner. The shortest participant was $152.4 \mathrm{~cm}$ (60 in) in height, the tallest was $195.6 \mathrm{~cm}$ (77 in) tall, and the mean \pm standard deviation $=175.0 \mathrm{~cm} \pm 9.6(68.9 \mathrm{in} \pm 3.7)$. The table height of the scanner was either $91.4 \mathrm{~cm}$ (36 in) or $106.7 \mathrm{~cm}$ (42 in) for each participant: the former is a recommended height based on the findings of an earlier fingerprint capture usability study [9], and the latter is the most common height used with fingerprint scanners at USVISIT stations [10]. Subjects were assigned to a table height in a counterbalanced fashion. Thirty people used the scanner at the lower $(91.4 \mathrm{~cm})$ table height; 32 people used the scanner at the higher $(106.7 \mathrm{~cm})$ height.

\subsection{RESEARCH QUESTIONS}

In this study we addressed the following questions:

- Did participants notice the slap icons and LED indicators on the scanner?

- Did the slap icons and LED indicators on the scanner help participants successfully capture their fingerprints?

- Did the US-VISIT poster help participants succeed in presenting their fingerprints in such a way that the system could capture quality images of them?

- How confident were participants that they used the scanner correctly?

- Secondary question: Would table height, on which the scanner rested, have any effect on performance in this study? 


\section{RESULTS}

In this section we present the qualitative and quantitative data resulting from the study. Subjects were asked to relate, "your impressions of what is happening as you use the device," as they worked through the task of presenting and having their fingerprints scanned. The observer recorded comments made by participants as they used the scanner and immediately following use. We present representative comments intermingled with the quantitative findings in an effort to let the data and participants relate the experience of using the scanner during this study.

\subsection{COMPLETING THE TASK}

\subsubsection{Overall print capture success}

Successful presentations were more the exception than the rule: the overall capture rate for participants' prints was very low. As shown in Table 1, only 10 of the 62 participants captured a full set of prints, 9 captured some but not all prints, and the remaining 43 participants failed to capture any prints at all.

Table 1: Overall fingerprint capture success rate

\begin{tabular}{c||c|c|c|c} 
Captured... & $\begin{array}{c}\text { Full set of } \\
\text { prints }\end{array}$ & $\begin{array}{c}\text { Some, but not } \\
\text { all prints }\end{array}$ & No prints & Total \\
\hline \hline $\begin{array}{c}\text { Number of } \\
\text { participants }\end{array}$ & 10 & 9 & 43 & 62 \\
\hline $\begin{array}{c}\text { Percentage of } \\
\text { participants }\end{array}$ & $16.1 \%$ & $14.5 \%$ & $69.4 \%$ & $100 \%$
\end{tabular}

Often participants did not know if they had successfully left prints or not, or could not ascertain if they had completed the task of having their fingerprints scanned. The following quotes from participants illustrate this issue:

- "Confusing... No feedback... if it had captured the images. No feedback to begin or end." [s1]

- "Did it work?" [s2]

- "Don't know when to stop or when to lift." "Don't know when it's done or when to lift." [s6]

- "Supposed to tell me when I should go to the next one?" [s7]

- "It was happenstance, chance that anything was captured." [s9] 
- "Do you just assume that it worked and go on?" [s12]

- "It doesn't beep or anything so am I just to assume it's working?" "I don't know if the process is completed or not." [s13]

- "How do I know when to go to the next one? Doesn't tell me when to go to the next one. Not user friendly at all. Hope they don't use this machine. They'll have people lined up all over the place. There are no instructions. It's not working." [s34]

Participants who successfully left a full set of prints also made observations about the process that included the following:

- "I was confused at first, but then I saw the green and red lights come on." [s38]

- "Don't know when to take my fingers off. All red. Red means no. Ok. Try again. Ok. You have to fit your fingers in where these little dashes are. Now all green." "That's the ticket." [s60]

\subsubsection{The capture process - researcher observations}

The researcher responsible for observing participants noted that when participants first presented their fingers for a scan, they would often carefully touch the platen, look up at the US-VISIT instructional poster, and then possibly note the LED lights on the scanner changing color from red to green.

Many participants placed at least one finger on the top half of the platen outside of the scanning area, did not press their fingers down on the platen hard enough to capture a clear image, and/or shifted their fingers around on the platen while the scanner was trying to detect them. Most participants, seeing that only some of the LED lights turned green, either assumed that the LED lights were scan progress indicators or that the LED lights were showing them that their slap had been captured.

Even if they correctly interpreted the LED lights as indicators that their fingers were properly positioned, participants often thought the scanner would capture their fingerprints more rapidly than it actually did. Even though participants reported that they expected to hear a beep upon successful capture, many participants lifted their fingers from the platen before the system actually processed the scan, and thought that the scanner had successfully captured images of their fingerprints when, in fact, it had not.

Also, if the scanner could not capture the expected slap image, it would continue until it either successfully captured a fingerprint image or moved on to the next slap in the sequence. Participants who mistook a successful capture for an unsuccessful capture would often move on to the next slap in the sequence before the scanner did, e.g., they would move from a right four-finger slap to a right thumb slap when the scanner was still trying to "find" the right four-finger slap. In such cases, the best possible outcome was a partial set of captured 
fingerprint images - and those images would be out of order, e.g., the scanner software would end up storing a right thumbprint for a right four-finger slap.

\subsection{NOTICING AND INTERPRETING THE AFFORDANCES}

Participants had the following potentially instructive indicators, as well as the US-VIST poster, on which to reply for guidance through the scanning process:

- Slap icons on the sides of the scanner platen

- LED lights above the scanner platen

- Beeps emitted by the scanner upon successful image capture

The researcher captured quotes both during the fingerprint capture process and while participants were discussing the diagram they had labeled. Excerpts from what participants related to the researcher and wrote during the post-task survey are provided in the following sections. Note that even through the researcher did not respond to comments that were posed as questions, some participants persisted in phrasing their comments in question form.

\subsubsection{During the capture process}

Not all participants spoke aloud during the fingerprint capture process, but for those who did, their comments were categorized according to the topic area whether that was an affordance or something else, for example, an illustration of general understanding. The remaining comments were grouped as Miscellaneous. The quotes provided here are representative of the comments provided, but it is not an exhaustive list, as numerous instances referring to a common theme were omitted. Some items contain [bracketed contextual information] to supplement the quote; direct quotes are always contained within quotation marks. A brief summary is provided for each category or subcategory.

\section{Slap Icons}

Comments on the slap icons fell into three groups: reflection on usability issues made by s5 and s43, noticing that an icon was lit but unchanging (s14 and s48), and finally the thought that these slap icons were active buttons (s25 and s38).

- "Should be brighter." [s5]

- "I see this is lit up, but it doesn't change." [s14]

- "Tap them?" [Pressed each one in turn.] [s25]

- "Do I have to press anything?" [s38] 
- "The graphics aren't clear. The thumb looks like it's pushing a card." [s43]

- "I see this is lit up. But it's not changing." [s48]

\section{LED Lights}

Participants had difficulty discerning the exact meaning of the LED lights. When they noticed them turning green, often they expressed that they thought this was a verification of some sort, although at times participants did not know what it meant at all. Unfortunately, a notion repeated by a number of participants was that a green light meant the print had been captured.

- "Should I leave them here? Or wait until they all turn green?" [s3]

- "Maybe the light'll go out. Now one of the lights is green, but I don't know if it's captured it. Frustrating." [s5]

- "Don't have a clue what to do next."'Confused by flashing lights." [s6]

- "They weren't all lighting up in the same way as on the others, so I took it upon myself to lift off." [s9]

- "Assuming it's a verification -- that green light." [s10]

- "Now I'm just playing around. I notice that the signal area [red/green lights] changes color as it captures." [s11]

- "Green light - does that mean it's not all there? Seriously?!" [s18]

- "What do the 4 lights mean?" [s21]

- "Green means it captured that finger." [s44]

- "Some have changed to green, but I don't know why." [s56]

\section{Beep}

The participant comments illustrate that not all participants received a beep and they expected some sort of confirmation that a print had been captured. S5's comment also illustrates that he did not know how to tell which slap was expected by the scanner.

- "Does it automatically scroll to the next one? If it beeped?" [s5]

- [After receiving a beep] "Yes!" [s43]

- "I haven't heard a beep. Am I doing it wrong?" [s61]

- "I would hope it would make noise to tell me if I did it the right way." [s62]

\section{Poster}

Regarding the poster, participants wanted more information about the process, and specifically requested was information regarding the lights and timing of the capture process. Additionally, one participant noted confusion that the platen depiction on the slap indicators 
was not consistent with the scanner in front of him, while another participant felt the poster was not particularly readable.

- "Wasn't very readable." [s1]

- "Confused. On the poster the dark part is on the bottom, but on the device it's on the top." [s8]

- "Would have been nice to have more about the lights, but I get that you're dealing with the language component here." [s24]

- "Should have just about how long to leave fingers on." [s25]

\section{Scanning Area}

When participants made comments regarding the scanning area, it usually reflected their uncertainty about where to position their fingers on the platen.

- "Am I supposed to get my fingers within the black lines?" [s4]

- "Whether to use the whole area or just part?" [s20]

- "I like the rubber feeling to it, but might be better to be able to lay your fingers down." [s28]

- "Does it need to be in where the little dots are? Or the whole thing?" [s59]

- "I don't know where to press. In the area that's light green?" [s62]

\section{Overall Understanding}

Comments in this category reflect participants general (lack of) understanding especially regarding if and when they had completed a capture and when it was time to move on. Additionally, some comments reflect participants' thoughts about finger placement and the lack of feedback if they had placed their fingers on the platen properly for capture.

- "I don't see any indication ... that anything has happened. I don't like the fact that it's not telling me anything." [s14]

- "When do I go on to the next one? Will know when to switch?" [On tip toes] "There's no light turning on." "Nothing indicating that it took. Would expect all 4 to turn green to show it scanned successfully." "There's no sound in any of them. Not seeing anything [more] to show it is doing anything." [s15]

- "Am I done? It doesn't... Okay, now I feel like an idiot. I'm so confused. Obviously, I'm not doing this right because the light on the right is still on." [s17]

- "Should I hear something when it's done? The two end lights are green. I should think there should be some type of sound. Maybe it's telling me... No idea if it recorded the first four. I have no idea what's going on." [s22]

- "Do I line 'em up with the dots? Do I pull them off? Ok. I'm just going to follow the procedure." [Points to the poster.] [s23] 
- "Nothing's happening. I saw the lights flash. Waiting for something to happen. Don't know if it's going to tell me to go to the next step. Not sure how long to stay here. Figure it would beep or lights would flash." [s25]

- "Would like for it to tell me when I'm done." [s28]

- "One green light. Is it gonna beep or anything when it's done? How long do I leave it there? Green light flashed. How long should I leave it here?... Oh! It beeped. Does that mean I take it off? Fourth green came on - Just thinking you wouldn't need to leave it on that long." [s30]

- "Should I take my hand off? It's like alien technology. The thumb light [icon] isn't on." [Moves on.] "Should I take my hand off?" [s31]

- "I guess just putting fingers... don't know when it's complete." [Had to turn her body to reach for the thumb.] "Oh, I see, when they all light up red, it means they're good to go... Maybe not. I wasn't sure... I think it's the green that makes it accepted." [s33]

- "How do I know when to go to the next one? Doesn't tell me when to go to the next one. Not user friendly at all. Hope they don't use this machine. They'll have people lined up all over the place. There are no instructions. It's not working. I feel real dumb right now." [s34]

- "Am I just supposed to follow the steps [on the poster]? When do I change fingers?" [s35]

- "No idea how long to leave my fingers on here. I see lights, but I have no idea if it's recording anything." [s36]

- "Oh, green lights. Which don't tell me anything. They're gone. Beep. No beep? Still nothing. One green light. And beep." [s37]

- "Not sure how long to keep it on there. Just a second, or...? It should have some sort of beep or something. Not sure what the green light is indicating as opposed to the 3 red ones. It needs some sort of feedback." [s40]

- "If the green is on, it read it? ... Did I get it? I don't know. I don't think so, cuz a green light came on but not all. I'll try again." [s42]

- "Should fingers be close or spread? I'm thinking how hard I should press. And how long?" [s53]

- "Doesn't tell me how long or hard or beep. Doesn't give me any guidance. How far up or back to put my fingers." [s56]

- "Don't know when to take my fingers off. All red. Red means no. Ok. Try again. Ok. You have to fit your fingers in where these little dashes are. Now all green." ... "That's the ticket." [s60]

\section{Miscellaneous}

Some of the comments in the Miscellaneous category were impressions of physical aspects of the device; while other comments reflected an emotional response produced by use of the device.

- "Green light is scary" [s1]

- " "If I was running late for my plane this would tick me off." [s44] 
- "Step 1 seems pretty obvious... I kind of expected it to beep when I'm done, but based on the lights... I'm waiting for them all to show up green. Can't get [my pinky] to stay green. Don't know if..." [s45]

- "The shape is awkward. The box is clunky." [s49]

- "My first time when I used it, I was scared, I asked my mother why they're doing this." [s57]

\subsubsection{Diagram labeling}

After completing the fingerprinting process, participants drew on the diagram shown in Figure 2. One example is shown in Figure 6.

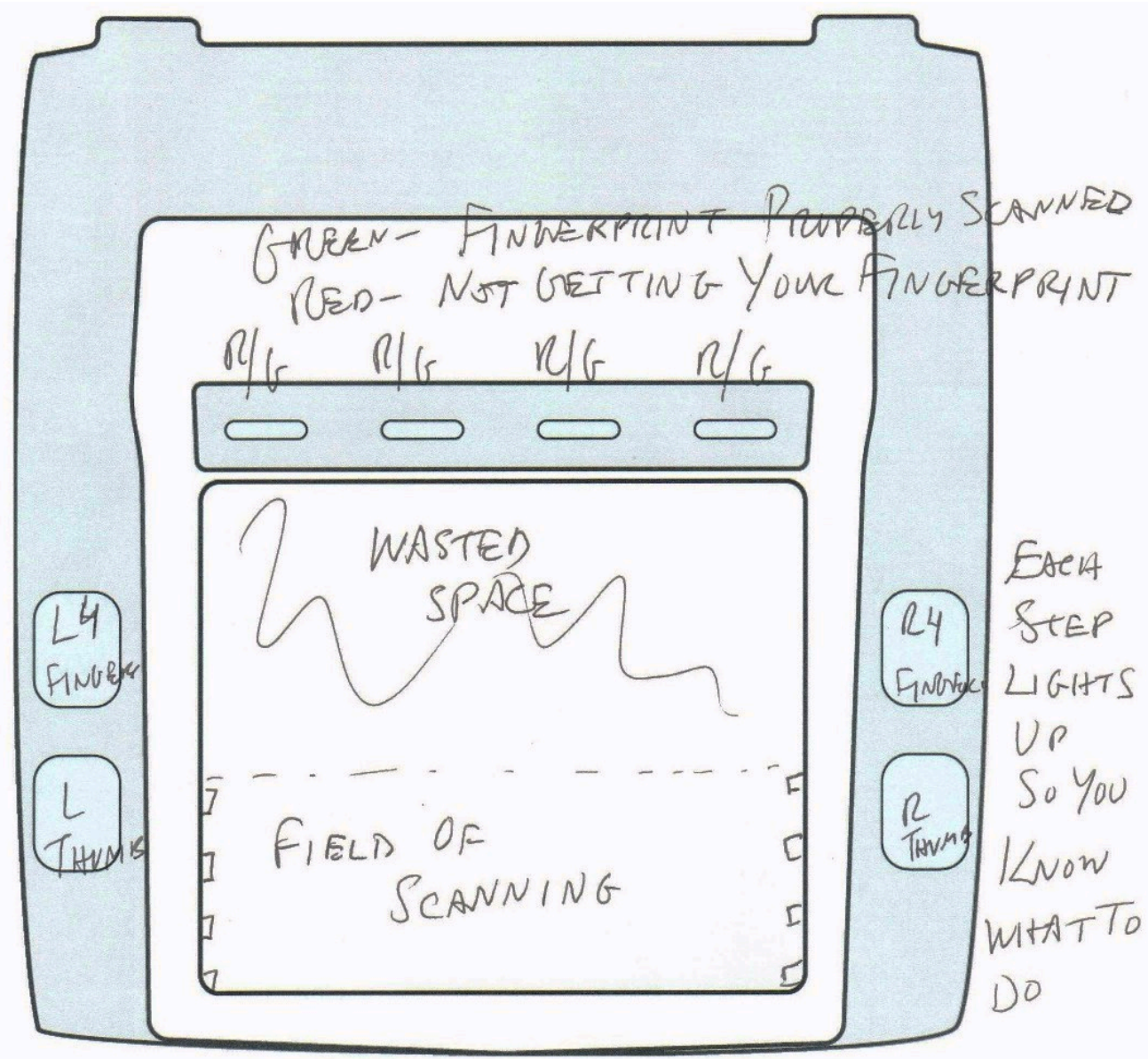

Figure 6: An example of a participant's scanner diagram where most features are labeled correctly 
The example above is very detailed and almost completely correct. The slap icons along the sides of the platen are correctly labeled and the participant clearly understood their purpose ("each step lights up so you know what to do"). The participant also correctly labeled the LED lights above the platen, however the interpretation of the function was incorrect - green light(s) indicate positioning is suitable for scanning, not that the fingerprint was "properly scanned”. In this case, the participant also outlined the scanning and non-scanning areas of the platen.

However, most participants did not label this many features correctly, if at all, in their scanner diagrams, such as the one in Figure 7 below.

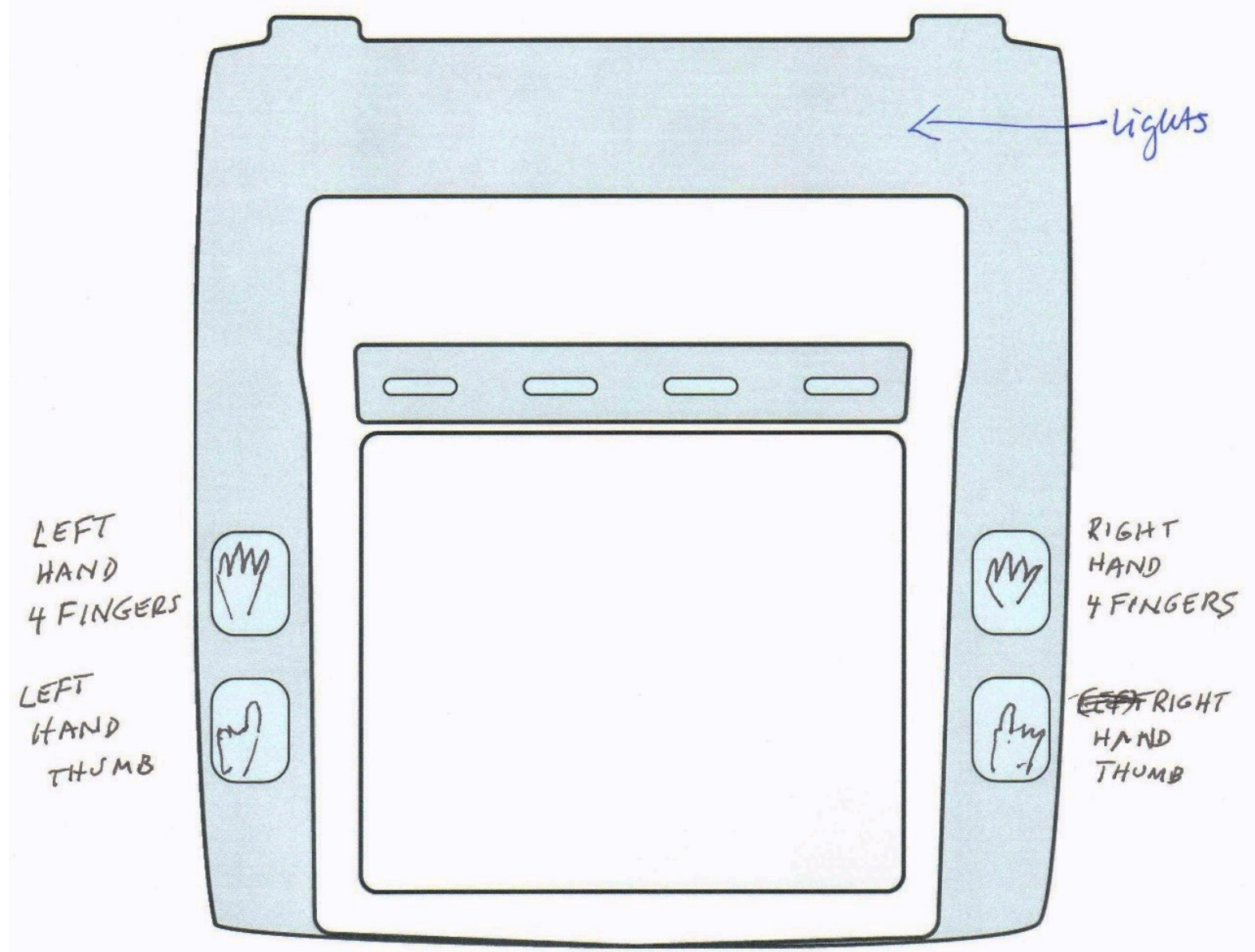

Figure 7: An example of a participant's scanner diagram where only some features are labeled correctly 
Notice that while this participant correctly labeled the slap icons, he/she did not seem to understand the purpose of the LED lights above the scanner platen. In fact, the participant's diagram indicates that he/she may have misremembered where the LED lights were actually located on the scanner. Some participants did not label the LED lights on their diagrams at all.

The diagram shown in Figure 8 is from a participant who did not capture any prints. This particular participant did notice the LED lights but did not understand their function. They did not notice the slap icons or experience the beep.

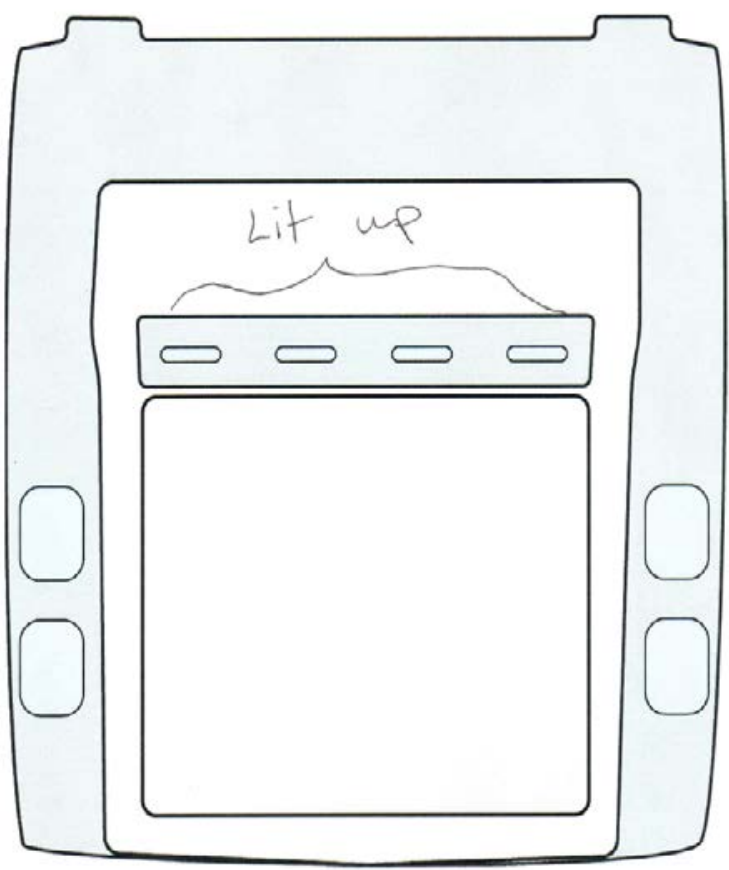

Figure 8: An example of a participant's scanner diagram with minimal labeling

Once participants had completed labeling the diagram of what they remembered of the scanner, the researcher determined for each affordance if 1 ) it was noted at all, 2) its function 
was described, and 3) its function was described correctly. Table 2 provides the counts of how participants labeled the diagrams according to how they fared in capturing prints.

Table 2: Diagram labeling summary

\begin{tabular}{|c|c|c|c|c|}
\hline \multirow[b]{2}{*}{ Affordance } & \multirow[b]{2}{*}{ Condition } & \multicolumn{3}{|c|}{ Prints captured } \\
\hline & & $\begin{array}{c}\text { All } \\
\mathrm{n}=10\end{array}$ & $\begin{array}{c}\begin{array}{c}\text { Some } \\
n=9\end{array} \\
\end{array}$ & $\begin{array}{c}\text { None } \\
n=43\end{array}$ \\
\hline \multirow{3}{*}{ Slap icons } & Notice Icons & $\begin{array}{c}9 \\
(90.0 \%) \\
\end{array}$ & $\begin{array}{c}2 \\
(22.2 \%) \\
\end{array}$ & $\begin{array}{c}25 \\
(58.1 \%) \\
\end{array}$ \\
\hline & $\begin{array}{l}\text { Provide labeling for } \\
\text { Icons }\end{array}$ & $\begin{array}{c}9 \\
(90.0 \%)\end{array}$ & $\begin{array}{c}2 \\
(22.2 \%)\end{array}$ & $\begin{array}{c}23 \\
(53.5 \%)\end{array}$ \\
\hline & $\begin{array}{c}\text { Correct labeling for } \\
\text { Icons }\end{array}$ & $\begin{array}{c}9 \\
(90.0 \%) \\
\end{array}$ & $\begin{array}{c}2 \\
(22.2 \%) \\
\end{array}$ & $\begin{array}{c}7 \\
(16.3 \%) \\
\end{array}$ \\
\hline \multirow{3}{*}{ LED lights } & Noted LEDs & $\begin{array}{c}10 \\
(100.0 \%) \\
\end{array}$ & $\begin{array}{c}9 \\
(100.0 \%) \\
\end{array}$ & $\begin{array}{c}38 \\
(88.4 \%) \\
\end{array}$ \\
\hline & $\begin{array}{c}\text { Provide labeling for } \\
\text { LEDs }\end{array}$ & $\begin{array}{c}10 \\
(100.0 \%)\end{array}$ & $\begin{array}{c}9 \\
(100.0 \%)\end{array}$ & $\begin{array}{c}37 \\
(86.0 \%)\end{array}$ \\
\hline & $\begin{array}{c}\text { Correct labeling for } \\
\text { LEDs }\end{array}$ & $\begin{array}{c}7 \\
(70.0 \%) \\
\end{array}$ & $\begin{array}{c}2 \\
(22.2 \%) \\
\end{array}$ & $\begin{array}{c}4 \\
(9.3 \%) \\
\end{array}$ \\
\hline \multirow{3}{*}{ Beep } & Notice beep & $\begin{array}{c}10 \\
(100.0 \%) \\
\end{array}$ & $\begin{array}{c}8 \\
(88.9 \%) \\
\end{array}$ & $\begin{array}{c}9 \\
(20.9 \%)\end{array}$ \\
\hline & $\begin{array}{c}\text { Provide description of } \\
\text { beep }\end{array}$ & $\begin{array}{c}10 \\
(100.0 \%) \\
\end{array}$ & $\begin{array}{c}8 \\
(88.9 \%)\end{array}$ & $\begin{array}{c}8 \\
(18.6 \%)\end{array}$ \\
\hline & $\begin{array}{c}\text { Correct description of } \\
\text { beep }\end{array}$ & $\begin{array}{c}10 \\
(100.0 \%)\end{array}$ & $\begin{array}{c}6 \\
(66.7 \%)\end{array}$ & $\begin{array}{c}4 \\
(9.3 \%)\end{array}$ \\
\hline
\end{tabular}

The data reflect that participants who captured all prints noticed and correctly interpreted the slap icons, LED lights, and beeps for the most part, although the number of participants who correctly interpreted the LED lights was lower than for the other affordances. The one person who did not notice the slap icons presumably followed the US-VISIT poster for the slap order. 
For the group of nine participants who captured some prints, relatively few noticed and correctly interpreted the slap icons (two of nine). However, all of them noticed and had some theory regarding the function of the LED lights, however relatively few correctly interpreted the LED lights (two of nine). Most of this set of nine noticed and had a theory as to the function of the beep (eight of nine), although six of nine correctly interpreted the meaning of the beep.

For the group of participants who did not capture any prints (n=43), 25 noticed the slap icons, while 23 had a theory as to their function, although only seven (16.3\%) correctly interpreted the meaning of the slap icons. 38 of 43 noticed the LED lights, although only four (9.3\%) participants actually correctly interpreted their meaning. Finally, regarding the beeps: six participants in this group actually received a beep at least once during their interaction with the scanner. Five of those six recall noticing the beep, while an additional four participants reported hearing a beep, even though they never received one (note that many participants reported expecting to hear a confirmation of capture), for a total of nine reporting hearing a beep. Four of the six who did receive a beep, correctly interpreted its meaning, even though the system did not ultimately store the image capture it had confirmed.

During the process of the researcher and the participant working through the labeling provided by the participant on the diagram, the researcher recorded comments made by the participant. A list of comments is provided here, which is not exhaustive, but is representative of the comments given by participants during this phase of the debriefing. Again, comments are grouped by topic with a short summary for each topic.

\section{Slap Icons}

While a few participants correctly interpreted the meaning of the icons, others did not. Some participants thought the slap icons were active buttons to be pushed. Some participants either had an incorrect interpretation slap icons or had no idea and were just confused by them. One participant commented that the symbol did not look like what it was supposed to represent a thumb.

Correct interpretation

- "Reminder of what you had to do. Guide you." [s18]

- "Which fingers to press." [s31]

- "Lit to guide additionally to say which set to place on the glass." [s45]

- "Showing me which fingers to put on the scanner, step by step." [s57]

Incorrect interpretation

- "Didn't notice the lights changing at all. Wasn't clear if these need to be pressed. Assumed when it lights up, the image was taken. Not too clear." [s14] 
- "Didn't know how to change to proceed." [s15] [Thought she needed to push it.]

Other observations

- "Originally thought that's where we start, but the light didn't go off, then one of these went green and the [icon] stayed lit. Pretty confusing." [s5]

- "I thought the light meant something, but I don't know if it did." [s25]

- [Symbol] "Doesn't look like a thumb, though." [s43]

- "Didn't really look at those." [s48]

- "Wasn't sure if these were buttons." [s51]

- "I don't think they meant anything." [s52]

- "Do I press them? To allow me to go on. At the time, I had no clue." [s55]

\section{LED Lights}

Some participants correctly interpreted the meaning of the LED lights, as reflected in some comments. Other participants did not interpret the exact meaning of the lights changing to green - they gathered that green meant proper positioning but then assigned additional meaning incorrectly, i.e., that green LED lights meant the fingerprint had been captured. Still others found them completely confusing or at best inconsistent.

Correct interpretation

- $\quad$ "There were red lights that didn't change. It was probably telling me that I wasn't doing it correctly. And there were no instructions about what to do." [s36]

Incorrect interpretation

- "No information given about them. Had to observe them change." "Indicators as to where to put them and after they turn green they've captured the image." [s3]

- $\quad$ "Completely confusing. Supposed to tell you when you were finished, but it made no sense to me." [s5]

- "I don't know. Green is go, red is stop, but it was intermittent what that meant when some were green and some were red." [s15]

- "Thought they were going to turn the same color when you were done. I assumed stop and wait for prints to be taken. Then green to go." [s17]

- "When a finger was processed, it turned green." [s21]

- "It didn't tell me anything. Though green would tell me it had taken the picture." [s25]

- "We were recorded. The lights were red." [s29]

Other observations

- "Didn't really catch if that was related to my fingers on the screen. Wasn't real clear about when I might have started and stopped that." [s2]

- "I don't know if they have to be all green at the same time." [s4] 
- "I remember the lights flashing, but I don't know what they were for." [s7]

- "Not sure. Didn't seem consistent." [s9]

- "Finger light indicators, telling you whether your finger was readable. If it wasn't readable, it was a red light." [s16]

- "When I put my hand on, it turned green." [Telling you?] "Nothing." [s31]

- "That it was done or that my fingers were pressing too hard or not hard enough." [s61]

\section{Beep}

Some participants did not recall hearing a beep, and in fact, they did not receive a beep, as they left no prints. Other participants correctly interpreted the beep to mean the fingerprint had been captured and they could lift their fingers and move on. Still others thought the beep was associated with a camera: one said it was a camera taking a picture of the fingerprint and the other participant said they thought their picture was being taken.

Correct interpretation

- "Completed with the step, move on." [s10]

- "Indicate the grouping had been successfully read." [s16]

Incorrect interpretation

- "You're finished, you can lift your hand up. You're done." [s18]

Other observations

- "I remember not hearing any sounds." [s14]

- "Camera taking the picture of the fingerprint." [It] "clicked like a camera." [s27]

- "I don't associate them with anything that was going on." [s46]

- "I thought there would be more to it, like a beep. But I didn't hear that." [s47]

- "I thought my picture was being taken." [s50]

\section{Poster}

Participants wanted the poster to provide more information than it did.

- "Would have been nice if it said on the poster that the green light would go on to say it's okay." [s24]

- [Poster was] "a distraction. For a poster that big, there's very little information on it." [s43]

\section{Scanning Area}

One participant commented that the platen was notably small.

- [Platen] "is very small. Kid size" [s1] 


\section{Overall Understanding}

Participants noted that they had trouble knowing if they had performed the process correctly or completely. They expected timely confirmations regarding when they thought they had completed a capture.

- $\quad$ "Kinda had to figure it out." "It wasn't really user friendly. The process is not going to be user friendly. I had problems with figuring out what to do. There was nothing to tell me what to do." [s34]

- "Pretty clear, except for the time. But there wasn't a time on the poster, so I just made an assumption." [s37]

- "Am I doing it wrong or correctly? Am I done with the process? Very confusing." [s39]

- [Used it] "to learn what to do first. Just used the picture. Wasn't sure when it was finished. I guess I was expecting some words, like 'Next." [s48]

- "It got the fingerprint. It buzzed, but it was so late you didn't know if you were done or not." [s52]

\section{Miscellaneous}

One participant remarked on the table height, which was uncomfortably high for that participant. Another participant seemed to expect the rolling aspect of the paper and ink fingerprint capture process to be included in this process. Additionally, the lack of timing indicators or a feeling of control of the process, such as pressing an "OK" button, was noted.

- The "table was a little high for me. I could reach, but it was hard. Uncomfortable." [s1]

- "Was a little confused about whether I [put one] finger or all my fingers and which direction to roll my fingers." [s21]

- "The steps were easy to figure out. I just needed to know how long I needed to keep my finger on the machine." [s25]

- "I imagined it to be like an ATM. I was frustrated that there was no timing involved. With computers, I know you need to press an OK button to go on, and there wasn't anything like that." [s55]

\subsubsection{What guided participants as they used the scanner - self-reported}

After discussing the participant's labeling of the diagram, the researcher asked the following question, "I am interested in what you considered to be the 'instructions' for the fingerprinting task. What did you use to help guide you when you used the scanner?"

Table 3 below provides counts of the indicators participants reported using to guide them through the fingerprint scanning process with respect to their success at having the scanner 
capture their fingerprints. It is important to note that some participants might have focused on the term "instructions" and did not interpret the question to include the entire set of instructive indicators. Inconsistencies between spoken comments recorded during the scanning process and reported affordance use raise this issue. In any case, the data is reported here as recorded immediately following the diagram labeling exercise.

Table 3: Instructional indicators used by participants and capture success

\begin{tabular}{r||c|c|c|c} 
& $\begin{array}{c}\text { Full set of } \\
\text { prints } \\
(\mathbf{n = 1 0 )}\end{array}$ & $\begin{array}{c}\text { Some } \\
\text { captured } \\
(\mathbf{n}=\mathbf{9})\end{array}$ & $\begin{array}{c}\text { None } \\
\text { captured } \\
(\mathbf{n}=\mathbf{4 3})\end{array}$ & Total \\
\hline Poster & 8 & 8 & 43 & 59 \\
\hline Slap Icons & 7 & 0 & 4 & 11 \\
\hline LED Lights & 3 & 1 & 2 & 6 \\
\hline Beep & 0 & 1 & 0 & 1
\end{tabular}

Participants who captured complete sets of prints reported that they considered either the USVISIT poster, the slap icons on the sides of the scanner platen, or both to be their "instructions" for using the scanner. Only 3 of the completely successful participants said that the LED lights provided them with instruction, and none regarded the beeps as instructive.

Many participants reported relying almost exclusively on the poster for guidance, as indicated by Table 4 below. Please note that the caveat given for the previous table regarding possible participant focus on the term "instructions" applies to this table as well.

Table 4: Participant reliance on instructional poster and capture success

\begin{tabular}{r||c|c|c|c} 
& $\begin{array}{r}\text { Full set of prints } \\
\mathbf{n = 1 0}\end{array}$ & $\begin{array}{c}\text { Some prints } \\
\mathbf{n = 9}\end{array}$ & $\begin{array}{c}\text { No prints } \\
\mathbf{n = 4 3}\end{array}$ & $\begin{array}{c}\text { All participants } \\
\mathbf{n = 6 2}\end{array}$ \\
\hline $\begin{array}{r}\text { Poster Only } \\
\text { Poster + Other } \\
\text { Indicator(s) }\end{array}$ & 2 & 8 & 37 & 47 \\
\hline $\begin{array}{r}\text { Other Indicator } \\
\text { Only }\end{array}$ & 2 & 0 & 6 & 12 \\
\hline $\begin{array}{r}\text { Ond } \\
\hline\end{array}$ & 2 & 1 & 0 & 3
\end{tabular}




\subsubsection{Instructive materials and indicators - helpfulness and clarity}

In addition to asking participants what they used as instructional indicators, the post-task questionnaire asked them to rate (on a five-point scale) the clarity and effectiveness of those indicators. Participants' ratings for what they regarded as "instructions" are shown in Table 5.

Table 5: Participants' ratings of the clarity and helpfulness of the US-VISIT poster

\begin{tabular}{|c|c|c|}
\hline Statement & Rating Scale & Average Rating \\
\hline $\begin{array}{l}\text { The instructions provided were effective in helping } \\
\text { me complete the fingerprint capture process. }\end{array}$ & $\begin{array}{l}1=\text { Ineffective } \\
2=\text { Somewhat effective } \\
3=\text { Effective } \\
4=\text { Very effective } \\
5=\text { Completely effective }\end{array}$ & $\begin{array}{l}2.40 \text { (Somewhat } \\
\text { effective) }\end{array}$ \\
\hline $\begin{array}{l}\text { The instructions provided clearly described the } \\
\text { fingerprint process. }\end{array}$ & $\begin{array}{l}1=\text { Unclear } \\
2=\text { Somewhat clear } \\
3=\text { Clear } \\
4=\text { Very clear } \\
5=\text { Intuitive }\end{array}$ & $\begin{array}{l}2.45 \text { (Somewhat } \\
\text { clear) }\end{array}$ \\
\hline The instructions provided were confusing. & $\begin{array}{l}1=\text { Not confusing } \\
2=\text { Somewhat confusing } \\
3=\text { Confusing } \\
4=\text { Fairly confusing } \\
5=\text { Very confusing }\end{array}$ & $\begin{array}{l}2.00 \text { (Somewhat } \\
\text { confusing) }\end{array}$ \\
\hline
\end{tabular}

Participants reported that the instructions provided were "somewhat effective" but not "effective" in helping them complete the fingerprinting task. With respect to clarity, participants rated the instructions as being only "somewhat clear" at describing the fingerprint process and "somewhat confusing" overall.

Participants also rated their clarity on various aspects of the fingerprinting process; the results are shown in Table 6. Understanding of the slap order was "clear", while how to position one’s self for fingerprinting was “somewhat clear”. Clarity surrounding key 
milestones within the fingerprinting process (beginning, ending, image capture) were all “unclear”.

Table 6: Participants' ratings of their clarity on aspects of the fingerprint process

\begin{tabular}{l|l|c}
\multicolumn{1}{c|}{ Statement } & \multicolumn{1}{c|}{ Rating Scale } & $\begin{array}{c}\text { Average } \\
\text { Rating }\end{array}$ \\
\hline \hline The order of the fingerprint capture was clear. & & 3.35 \\
\hline It was clear how to position yourself for the fingerprinting. & $\begin{array}{l}1=\text { Unclear } \\
2=\text { Somewhat clear } \\
3=\text { Clear } \\
\text { It was clear when the fingerprint image had been taken. } \\
\text { It was clear when the fingerprint process began. }\end{array}$ & 2.58 \\
\cline { 1 - 3 } It was clear when the fingerprint process ended. & & 1.84 \\
\cline { 2 - 3 } & & 1.85 \\
\cline { 3 - 3 } & & 1.87
\end{tabular}

\subsubsection{Confidence and capture success}

When asked "How confident are you that you completed the fingerprint task as intended?" on the post-task survey, participants gave an average rating of 2.1 ("Somewhat confident"). A 5point scale was used, other response choices for this question were as follows: 1 being "Not Confident,” 3 being “Confident,” 4 being "Very Confident,” and 5 being “Certain”.

Participants who successfully captured a full set of prints had an average confidence rating of 3.2 (“Confident”), while those who were unsuccessful had an average of 1.7 and 1.9, not quite at the "Somewhat confident" mark, for those who left some prints and no prints, respectively. The confidence levels with their respective standard error calculations are shown in Table 7.

Table 7: Participant confidence scores and capture success (mean \pm SE)

\begin{tabular}{c||c|c|c|c} 
& $\begin{array}{c}\text { Full set of } \\
\text { prints } \\
\mathbf{n = 1 0}\end{array}$ & $\begin{array}{c}\text { Some but } \\
\text { not all prints } \\
\mathbf{n}=\mathbf{9}\end{array}$ & $\begin{array}{c}\text { No prints } \\
\mathbf{n}=\mathbf{4 3}\end{array}$ & $\begin{array}{c}\text { Total } \\
\mathbf{n}=\mathbf{6 2}\end{array}$ \\
\hline \hline Confidence & $3.2 \pm 0.4$ & $1.7 \pm 0.4$ & $1.9 \pm 0.2$ & $2.1 \pm 0.1$
\end{tabular}

Participants who had a full set of prints captured had a statistically significantly higher level of confidence $(\mathrm{p}<0.01)$ compared with the other two groups whose participants did not leave 
a full set of prints (using Student's t-test to determine if sets of data are significantly different from each other). Having said that, none of the participants in this study were particularly confident that they had used the scanner correctly. The average confidence scores from successful and unsuccessful participants suggest that many people knew or suspected that they were not using the scanner correctly and that they felt it was unlikely they had successfully captured prints. On average, successful participants were only "confident," rather than "very confident" or "certain" that they completed the fingerprinting task as intended.

\subsection{WHAT PARTICIPANTS FOUND TO BE CONFUSING}

When asked on the post-task questionnaire, "What was the most confusing part of the process?,” participants provided insight into why their confidence levels were so low. Note that some participants provided several items they found confusing.

Overwhelmingly, 41 of 62 participants cited issues related to perceived lack of guidance and feedback during their progression through the task, e.g., how long to leave fingers on the platen for the capture to complete and when to move to the next slap, were given most often as confusing aspects of the overall task. Participant comments on this topic include the following:

- "How long to hold my fingers down and if the image was captured successfully." [s5]

- "When to proceed to the next step; when the scanning began." [s6]

- "Needed a clear signal of where to switch fingers" [s7]

- "I didn't know when images were completed nor when to continue." [s9]

- "What, if anything, to do with the buttons, whether to wait for a beep or instructions. How long to wait between procedures." [s10]

- "Unclear of the timing in the fingerprinting process. Unsure if my fingerprints have been captured." [s11]

- "To know when the image was captured or not and when to move on to the other side." [s12]

- "Knowing when an image had been taken" [s14]

- "Not knowing if I did things correctly, if the scan actually worked during each process, when to start and when to finish." [s15]

- "Know when the process started. When to move on to the next step. The next step (how long to leave my hand on the machine). When process is complete." [s23]

- "Not sure when to move to the next position of fingerprint." [s33]

- "Not being guided and not knowing if the scan had taken or when it was over." [s46]

- "Not knowing if the scanner was reading the image; not knowing if/when finished" [s58] 
Where to place fingers on the platen was also noted as an area of confusion. Participants reported the following:

- "Where is the rectangle part you're supposed to work within?" [s8]

- "Knowing where to place my fingers" [s16]

- "Where exactly on the glass to place digits." [s44]

- "Where to place your fingers. Is anywhere ok?" [s59]

Other participants cited the lack of instruction to be the most confusing aspect of the task with the following comments:

- "Not having some written instructions." [s2]

- "Lack of instruction on how the machine worked." [s3]

- "Not having clear instructions" [s13]

- "No instructions of start/finish" [s47]

- "Only instructions were which hand to use -- not how long --or follow the light -- listen for the beep, etc." [s56]

Some participants expressed that the LED lights were the most confusing aspect for them and provided the following comments:

- "The lights did not if all four lights needs to be green when I put only one finger." [s27]

- "Figuring out that the lights individually indicated it was sensing your prints they look like progress bars." [s43]

- "I didn't understand what the lights mean" [s57]

One participant wanted a way to correct a perceived mistake and stated it this way:

- "If you make a mistake how do you reset the system." [s59]

Three of the ten fully successful participants found confusing aspects of the task as well, and provided the following insights:

- "Not sure it actually scanned my fingerprints. If it could say scan complete that would tell me for sure that it was completed properly." [s32]

- "When I had to go to the next step." [s34]

- $\quad$ "Figuring out on which part of the glass to place my fingers. It was obvious I was doing it wrong but not super intuitive how to do it right." [s45] 
Several participants who did not manage to have any fingerprints captured, had interesting observations on what they found most confusing. Their comments follow below:

- "Nothing" [s4]

- "The first step. The rest was clear" [s24]

- "None" [s29]

- "They was hardly any buzzing when I completed the task. I did not know I was finished when I completed my task." [s52]

\subsection{PARTICIPANT-REPORTED LESSONS LEARNED}

The post-task questionnaire asked participants, "Would you do anything differently next time?" Nineteen of the 62 participants said they wouldn't do anything differently. Of these participants, only three were from the fully successful group of ten. Of the remaining seven fully successful participants, two did not provide feedback to this question, while another merely responded with "Yes". The remaining four participants provided the following comments:

- "Take a closer look at visual markings on the pad" [s16]

- "Yes, I would not put my whole hand on the screen, only the four fingers as indicated in the instructions." [s34]

- "Start off pressing curved fingers, not held straight like in the graphic." [s43]

- "Position my fingers in the target box" [s54]

19 other participants said that they would request clearer feedback, instructions and/or assistance from the system operator either before or during the fingerprinting process. Some participants were more specific than others about how and what they would request. Representative comments follow:

- "Request clearer instructions" [s1]

- "Inquire about the time necessary to capture the fingerprints. Inquire about the signals that ensured successful capture of the fingerprints. Inquire about the placement of my finger on the machine" [s11]

- "Ask questions before beginning. Step by step instructions." [s15]

- "Ask if I was doing it right as I put my different fingers on the scanner" [s26]

- "Maybe ask when to start and if I would be told when to move on." [s46]

- "Ask questions" [s56] 
Of these 19, three specifically wanted verbal instruction - indicating a lack of confidence in their use of the icons, lights, beeps, and written instruction to proceed through the task. These comments are provided next:

- "Seek verbal guidance" [s6]

- "I also needs a voice that give step by step directions." [s52]

- "Voice instructions timed" [s55]

Some participants noted that they would look for certain features on the scanner or change their behaviors if they could perform the fingerprinting process over again. Their comments included the following:

- "Make sure all the lights turned green before moving on." [s4]

- "Pay attention to the red \& green light" [s7]

- "Take a closer look at visual markings on the pad" [s16] (Noted previously)

- "Maybe do one finger at a time and wait until all of the lights turned green." [s21]

- "Look at the color and patterns of the light on the scanner" [s24]

- "Wait for a beep. ON first use, I thought I was finished when I saw 4 lights." [s28]

- "Yes, I would not put my whole hand on the screen, only the four fingers as indicated in the instructions." [34] (Noted previously)

- "Start off pressing curved fingers, not held straight like in the graphic." [s43] (Noted previously)

- "Position my fingers in the target box" [s54] (Noted previously)

Some participants had mistaken impressions of changed behaviors that would be successful if they could perform the fingerprinting process over again.

- "I would first press the button indicating the fingerprints in play. I would then be careful to not let the fingerprints extend above (beyond) the four dashes on the side." [s10]

- "Move on after putting my 4 fingers down, not wait for green lights" [s19]

- "Check to see if the displays on the sides are buttons" [s51]

\subsection{OTHER EFFECTS}

\subsubsection{Effects of subject demographics on capture success}

Table 8 provides the capture success of participants shown with respect to gender. Of the 10 participants who were fully successful at completing the task, 3 were female and 7 were male. For participants who were partially successful, 3 were female and 6 were male. Finally, of the 43 participants who did not have any prints captured, 26 were female and 17 were male. Although it has been shown in earlier studies that men are more likely to capture 
quality prints than women [8], no further analysis of an effect from gender is warranted in this data due to the small number of female participants who were fully and partially successful at capturing fingerprints.

Table 8: Capture success by gender

\begin{tabular}{l||c|c|c|c} 
& $\begin{array}{c}\text { Full set of prints } \\
\mathbf{n = 1 0}\end{array}$ & $\begin{array}{c}\text { Some but not } \\
\text { all prints } \\
\mathbf{n = 9}\end{array}$ & $\begin{array}{c}\text { No prints } \\
\mathbf{n = 4 3}\end{array}$ & $\begin{array}{c}\text { Total } \\
\mathbf{n}=\mathbf{6 2}\end{array}$ \\
\hline \hline Female & 3 & 3 & 26 & 32 \\
\hline Male & 7 & 6 & 17 & 30
\end{tabular}

Table 9 shows the average age of participants with respect to how successful they were in having fingerprints captured. The average age of the participants in this study was 38.3 years \pm 4.9. Participant age had no statistically significant effect on capture success in this study.

Table 9: Capture success and age (Mean \pm SE)

\begin{tabular}{c||c|c|c|c} 
& $\begin{array}{c}\text { Full set of } \\
\text { prints } \\
\mathbf{n}=\mathbf{1 0}\end{array}$ & $\begin{array}{c}\text { Some but } \\
\text { not all prints } \\
\mathbf{n}=\mathbf{9}\end{array}$ & $\begin{array}{c}\text { No prints } \\
\mathbf{n}=\mathbf{4 3}\end{array}$ & $\begin{array}{c}\text { Total } \\
\mathbf{n}=\mathbf{6 2}\end{array}$ \\
\hline \hline Age & $35.4 \pm 11.2$ & $46.2 \pm 15.4$ & $37.4 \pm 5.7$ & $38.3 \pm 4.9$
\end{tabular}

\subsubsection{Print quality - threshold and results}

Overall, the fingerprints that were captured by the scanner were of good quality. Table 10 shows the average quality score of captured prints, using the NFIQ algorithm. These were quite good - close to the optimal NFIQ score of 1.

One factor affecting this high average score, was that the scanner software was set to capture and store fingerprint images with a threshold score of 3 or better for its proprietary quality assessment, resulting in high quality prints that were captured. 
Table 10: Fingerprint capture success and quality (NFIQ)

\begin{tabular}{r||c|c|c|c} 
& $\begin{array}{c}\text { Full set of } \\
\text { prints } \\
\mathbf{n = 1 0}\end{array}$ & $\begin{array}{c}\text { Some but not } \\
\text { all prints } \\
\mathbf{n = 9}\end{array}$ & No prints & $\begin{array}{c}\text { All prints } \\
\text { captured } \\
\mathbf{n = 1 9}\end{array}$ \\
\hline $\begin{array}{r}\text { Average Print } \\
\text { Quality Score } \\
\text { (NFIQ) }\end{array}$ & 1.79 & 1.55 & $\mathrm{n} / \mathrm{a}$ & 1.68
\end{tabular}

\subsubsection{Number of attempts to make a successful slap}

We observed a difference in number of slap attempts and capture success. The average number of attempts for each capture success group is displayed in Table 11 below.

Table 11: Average number of slap attempts and capture success

\begin{tabular}{c||c|c|c} 
& $\begin{array}{c}\text { Full set of prints } \\
\mathbf{n = 1 0}\end{array}$ & $\begin{array}{c}\text { Some but not all } \\
\mathbf{n = 9}\end{array}$ & $\begin{array}{c}\text { No prints } \\
\mathbf{n = 4 3}\end{array}$ \\
\hline \hline $\begin{array}{c}\text { Right slap } \\
\text { attempts }\end{array}$ & 4.3 & 2.3 & 1.7 \\
\hline $\begin{array}{c}\text { Right Thumb } \\
\text { Attempts }\end{array}$ & 2.0 & 1.4 & 1.3 \\
\hline $\begin{array}{c}\text { Left Slap } \\
\text { Attempts }\end{array}$ & 1.8 & 2.2 & 1.4 \\
\hline $\begin{array}{c}\text { Left Thumb } \\
\text { Attempts }\end{array}$ & 1.5 & 1.4 & 1.2 \\
\hline Total & 9.6 & 7.4 & 5.6
\end{tabular}

Notably, participants in the fully successful group tended to make more attempts on the first slap and once successful, the number of attempts to complete each subsequent slap generally trended downward. On average, participants who succeeded at capturing a full set of prints needed 4.3 attempts to complete the initial right slap and 2 attempts to complete the right thumb slap. They needed slightly fewer tries to capture the left slap (1.8) and 1.5 for the left thumb slap. The 10 participants (6.2\% of the total) who captured complete sets of prints 
made a total of 96 slap attempts (40 would be the fewest expected - one attempt for each slap for each participant), with an average of 9.6 slaps each.

Other participants made fewer attempts on the initial slap and were not as successful capturing fingerprints overall.

\subsubsection{Effects of software crashes}

Some unexpected interactions between the system configuration and LSMS scanning software led to system crashes. Although we performed extensive testing on the scanner after all our participants were finished going through the procedure, we were unable to consistently reproduce the error and are unsure of the cause. Crashes did not occur during use of the system prior to participant involvement.

Twelve of the 62 participants - from both successful and unsuccessful groups - experienced this problem. When the system crashed, the researcher would have participants sit in a chair away from the fingerprinting device and ask them questions from the post-task questionnaire while he/she restarted the system. From what we observed, the crashes had no noticeable effect on their performance during the scanning process, or on the views they expressed during and after the process.

\subsubsection{Effects of scanner height on capture success}

Scanner height did not have any noticeable effect on capture success, image quality, or user confidence. Previous studies [9] have shown that a large number of trials, several hundred, are typically performed to see the effect of table height on capture success. Since so relatively few of the participants in this study were successful, it would have been surprising to see the effect.

Although an effect was not discernible in the data, one participant mentioned the scanner height as being too high in the following comment, "[The] table was a little high for me. I could reach, but it was hard. Uncomfortable." [s1]. While another participant was observed standing on her tip toes to look at the scanner while attempting to perform the assigned task.

\section{DISCUSSION OF THE OBSERVATIONS}

From the data, several themes emerge and are discussed below. All are related to the effectiveness of capturing a quality fingerprint. In this study, age, gender, scanner height and 
software crashes did not have statistically significant effects, although previous, larger studies have shown effects of age, gender and scanner height.

\subsection{WILLINGNESS TO EXPERIMENT}

Participants who succeeded in capturing all ten fingerprints made more attempts to complete each slap on average than participants who captured only partial sets of prints or no prints at all, data shown in Section 4.5.3. Successful participants appeared to use their slap attempts to learn the proper use of the scanner through experimentation, examining and learning the purpose of the LED lights, slap icons, and beeps as they did so. Their willingness to experiment with the scanner may well have contributed to their success.

\subsection{QUALITY THRESHOLD}

The quality acceptance setting used by LSMS appears to have winnowed the set of scanned fingerprints into a set of captured fingerprints with generally high quality, as assessed with the NFIQ algorithm. There is no doubt that if the quality threshold for the scanner had been set to allow the capture of prints of lower quality, it is possible that more participants may have captured more prints. What is not clear is 1) if the additional prints captured would have been of acceptable quality for DHS purposes and 2) if participants would have understood the process better or just happened to capture more prints. Since many participants did not notice or interpret correctly the instructional indicators, the overall positive effect of a reduced quality threshold remains questionable.

That said, for the relatively small number of fingerprints the scanner did capture, it was effective at capturing prints of adequate quality.

\subsection{LACK OF CLARITY}

Because participants did not receive any guidance, instruction, or assistance from the researcher/operator when they used the scanner, they had to rely on the US-VISIT instructional poster, slap icons, LED lights, and beeps for instructions and feedback during the task. Often participants, when they did notice the affordances, had difficulty interpreting their meanings. This lack of clarity of the affordances' meanings likely led to the low confidence ratings, shown even among successful participants. For example, [s32] who captured all prints commented: "Not sure it actually scanned my fingerprints. If it could say 'scan complete' that would tell me for sure that it was completed properly." Another indication of this lack of clarity was revealed by 3 participants who suggested that instructions should be presented by a person, e.g., "someone telling you the steps," [s21] when asked for any additional comments or suggestions. 
That said, participants did not relate to all of the instructional indicators in the same way, although certain patterns emerged. We discuss our findings related to each of the instructional indicators below.

\subsubsection{Instructional poster}

In their post-task debriefing, most participants (59 of 62) said that they used the US-VISIT poster as an instructional indicator to help guide them through using the fingerprint scanner. We discovered that some successful participants used the poster in combination with other cues - such as the slap icons and LED lights - to help them use the fingerprint scanner effectively, while unsuccessful participants relied more heavily on the poster to guide them. This result was consistent with findings from a previous fingerprinting study involving a similar instructional poster [11]. There are two reasons why the poster may have negatively affected the performance of participants who relied heavily on it.

First, while the poster indicated proper finger positioning for the model of scanner being used, it still left many participants unsure of how to place their fingers properly. The graphics on the poster depicted the scanning area (on the lower half of the scanner platen) as being darker than the non-scanning area: several participants remarked that the reverse was true on the scanning device. Some participants may also have been confused because, while the pictures on the US-VISIT poster seemed to indicate that one should hold one's fingers straight when presenting a four-finger slap, not everyone could fit the pads of their fingers in the scanning area when holding them this way - some individuals must bend the middle finger slightly to bring all four fingers into the scanning area.

Second, the poster only went as far as explaining the proper slap sequence and finger positioning. It did not say how long participants should hold their fingers on the platen or how much pressure they should apply. It also did not mention or explain features on the scanner that participants could have used for guidance and feedback - the slap icons, LED lights, and beeps. This is likely part of the reason why many participants did not correctly interpret the first two features, and did not know that they should expect the third as confirmation of a successful capture.

\subsubsection{Slap icons}

When filling out the blank diagram of the scanner, $58.1 \%$ of participants (36 of 62), indicated they noticed the slap icons along the sides of the scanner platen, however, only 18 (29.0 \%) labeled them correctly, i.e., could relate their function. Further, only 11 (17.7\%) reported using the icons for guidance through the task. Of the participants who noticed, but did not discern the actual function of the slap icons, some said the slap icons were buttons, 
mistaking them for features on the scanner that could support interaction, rather than providing guidance.

In a broad sense, the purpose of the icons was intended to provide users with the slap order. Whether participants used the icons, the poster, or a combination of both, participants typically presented slaps in the proper order. Since this was presented quite clearly on the poster, there is no way to discern if the slap icons succeeded in supporting this broad purpose. Beyond the order, the lack of guidance regarding which slap the scanner expected at any particular time during the overall task, left most participants expressing confusion. [s14] related it this way, "Didn't notice the lights changing at all. Wasn't clear if these need to be pressed. Assumed when it lights up, the image was taken. Not too clear." In this respect the slap icons generally provided little or no guidance.

\subsubsection{LED lights}

All of the ten participants who captured full sets of prints marked the LED lights on the scanner diagrams given to them after the fingerprinting task, although only 7 of them labeled the LED lights correctly. Most participants who noticed some of the LED lights turning from red to green during the fingerprinting process either assumed that the LED lights were progress indicators or were showing that their slap had been captured by the scanner. Participants who said they thought the LED lights were progress indicators typically had placed their fingers only slightly incorrectly; the problem was usually the middle finger, which reached out of the scanning area. Some participants inferred that the LED lights were related to placement correctness; and, these participants were likely to make multiple attempts to present a slap. As previously noted, the more attempts a participant made, the more likely he/she was to succeed in capturing a partial or complete set of fingerprints.

\subsubsection{Beeps}

When they received them, many participants were able to deduce the correct meaning of the beeps, partially because they expected some sort of confirmation of the capture process.

However, some of these participants remarked that the confirmation came so much later after they expected it, that it actually caused confusion as to what was actually happening in the process. One participant related the experience in this way, "I don't associate them with anything that was going on." [s46] 


\subsection{PULLING IT ALL TOGETHER - TIMING CUES}

Overall, participants reported being unclear about when the fingerprint process started, ended, when a fingerprint was actually captured (shown in Table 6), and by extension, when to progress to the next slap. This lack of clarity regarding cues in the process was decidedly cited the most often when participants were asked to comment on what they found the most confusing (Section 4.3). It may have contributed to the generally low confidence ratings as well. Comments given by participants during the fingerprint capture task, provided in the Overall Understanding category in 4.2.1, often reflect participants' ability to correctly interpret one or two of the indicators, but correctly interpreting them all and using those correct interpretations to move through the task effectively, was much rarer. Even participants who were successful at capturing fingerprints remarked on the lack of timing cues to support them in completing the task successfully and confidently.

\subsection{OVERALL SUITABILITY OF SCANNER FOR SELF-SERVICE USE}

It is clear that the poster and scanner affordances alone did not provide the information and cues most participants needed to present all their slaps correctly. The US-VISIT poster provided helpful - but not complete - instructions on what participants were expected to do during the fingerprinting process. Many participants did not notice the slap icons and LED lights or, if they did, misinterpreted what those things meant. These factors contributed to a high failure rate in terms of successful print capture: 43 of our 62 participants ( $69.4 \%$ ) did not succeed in capturing any prints at all.

Since this failure rate would be unacceptable for a self-service fingerprint capture device in the real world (or indeed any fingerprint capture device), it is evident that the scanner and instructional materials used in this study, if implemented in the US-VISIT program would be insufficient to serve that purpose on their own.

\section{CONCLUSION}

In the real world, users receive guidance and feedback from a Customs and Border Protection officer when undergoing the fingerprinting process with the scanner and poster employed in this study. Based on our observations and feedback from participants, removing the guidance of a human operator from the equation makes it much more difficult - even impossible - for users to successfully present their fingerprints to the scanner in such a way that the scanner can capture a full set of fingerprint images. The US-VISIT poster and 
scanner affordances alone did not provide users with the information and cues they needed to evaluate (and, if necessary, correct) their performance.

A self-service fingerprinting solution will have to include considerably more user feedback, instruction, or both than offered by the fingerprint scanner and US-VISIT poster used in this study. Developing a truly effective self-service solution will require extensive research and testing: this study helps to define the parameters for that future work. 


\section{REFERENCES}

[1] ISO 9241-210:2010 Ergonomics of human-system interaction - Part 210: Humancentred design for interactive systems.

[2] Koslowski, R. (2005). Real challenges for virtual borders: The implementation of US-VISIT. Newark, NJ: Migration Policy Institute. Retrieved February 27, 2013 from http://www.migrationpolicy.org/pubs/Koslowski_report.pdf.

[3] NIST Information Technology Laboratory, Information Access Division, Image Group. (2012, August 8). NIST Biometric Image Software. NIST Information Technology Laboratory. Retrieved February 27, 2013 from http://www.nist.gov/itl/iad/ig/nbis.cfm.

[4] Norman, D. (2007). Affordances and design. Jnd.org. Retrieved February 27, 2013 from http://jnd.org/dn.mss/affordances_and_design.html

[5] Micheals, R., Stanton, B., Theofanos, M., and Orandi, S. U.S. Department of Commerce, National Institute of Standards and Technology (NIST). (2006). A taxonomy of definitions for usability studies in biometrics (NIST IR 7378). Retrieved February 27, 2013 from http://www.nist.gov/customcf/get_pdf.cfm?pub_id=50911

[6] Tabassi, E., Wilson, C., and Watson, C. U.S. Department of Commerce, National Institute of Standards and Technology (NIST). (2004). Fingerprint image quality (NIST IR 7151). Retrieved February 27, 2013 from http://www.nist.gov/customcf/get_pdf.cfm?pub_id=905710.

[7] Theofanos, M., Stanton, B., Sheppard, C., Micheals, S., Choong, Y., Wydler, J., Mangold, K., Steves, M., and Morse, E. U.S. Department of Commerce, National Institute of Standards and Technology (NIST). (2008). Assessing face overlay (NIST IR 7578). Retrieved February 27, 2013 from http://www.nist.gov/customcf/get_pdf.cfm?pub_id=902148.

[8] Theofanos, M., Micheals, R., Scholtz, J., Morse, E., \& May, P. (2006, April). Does habituation affect fingerprint quality? Proceeding CHI '06 Extended Abstracts on Human Factors in Computing Systems, 1427-1432. doi: 10.1145/1125451.1125714. 
[9] Theofanos, M., Orandi, S., Micheals, R., Stanton, B., and Zhang, N. F. U.S. Department of Commerce, National Institute of Standards and Technology (NIST). (2007). Effects of scanner height on fingerprint capture (NIST IR 7382). Retrieved February 27, 2013 from http://www.nist.gov/customcf/get_pdf.cfm?pub_id=50903.

[10] Theofanos, M., Stanton, B., Sheppard, C., Micheals, S., Zhang, N. F., Wydler, J., Nadel, L., and Rubin, W. U.S. Department of Commerce, National Institute of Standards and Technology (NIST). (2008). Usability testing of height and angles of ten-print fingerprint capture (NIST IR 7504). Retrieved February 27, 2013 from http://www.nist.gov/customcf/get_pdf.cfm?pub_id=152149.

[11] Theofanos, M., Stanton, B., Orandi, S., Micheals, R., and Zhang, N. F. U.S. Department of Commerce, National Institute of Standards and Technology (NIST). (2007). Usability testing of ten-print fingerprint capture (NIST IR 7403). Retrieved February 27, 2013 from http://www.nist.gov/customcf/get_pdf.cfm?pub_id=51123. 


\section{APPENDIX A: USER DEMOGRAPHIC SURVEY}

Biometric Modality:

Date:

\section{Demographic Questionnaire}

1. Age:

1. Gender: (circle one) male female

2. Height:

feet inches

3. Ethnicity:

4. Profession:

5. Country of Origin:

6. Which hand do you use to write? (circle one) right left both

7. Have you ever had your biometrics captured before? (circle one) yes no If yes, check all that apply:

Fingerprinted with ink/paper Fingerprinted electronically 


__ Palm Print
E__ Eye Scan
Face Image
Voice
_ Hand geometry




\section{APPENDIX B: FINGERPRINT SCANNER DATASHEET}

Scanner height:

high

low

Participant \#

\section{PRESENTATION ORDER}

\begin{tabular}{|c|c|c|c|c|c|c|c|c|c|c|c|c|c|}
\hline \multirow[b]{2}{*}{ Right slap } & \multicolumn{4}{|c|}{ Order } & \multicolumn{4}{|c|}{ \# Attempts } & \multicolumn{2}{|c|}{ Collected? } & \multicolumn{2}{|c|}{ Collected correctly? } & \multirow[t]{2}{*}{ Comments / Questions / Behaviors } \\
\hline & 1 & 2 & 3 & 4 & 1 & 2 & 3 & 4 & Y & $\mathrm{N}$ & Y & $\mathrm{N}$ & \\
\hline Right thumb & 1 & 2 & 3 & 4 & 1 & 2 & 3 & 4 & Y & $\mathrm{N}$ & Y & $\mathrm{N}$ & \\
\hline Left slap & 1 & 2 & 3 & 4 & 1 & 2 & 3 & 4 & Y & $\mathrm{N}$ & Y & $\mathrm{N}$ & \\
\hline Left thumb & 1 & 2 & 3 & 4 & 1 & 2 & 3 & 4 & Y & N & Y & $\mathrm{N}$ & \\
\hline
\end{tabular}

\section{SCANNER INTERACTIONS}




\begin{tabular}{l|l|l|l}
\hline & Notice? & Understand? & Comments / Questions / Behaviors \\
\hline $\begin{array}{l}\text { Red/green } \\
\text { lights }\end{array}$ & $y / n / u$ & $y / n / u$ & \\
\hline Icon lights & $y / n / u$ & $y / n / u$ & \\
\hline
\end{tabular}

\begin{tabular}{l|l|l|l|l|l}
\hline & Notice? & Understand? & $\begin{array}{l}\text { Used } \\
\text { whole } \\
\text { glass }\end{array}$ & $\begin{array}{l}\text { Used } \\
\text { bottom } \\
\text { scan } \\
\text { area }\end{array}$ & Comments / Questions / Behaviors \\
\hline $\begin{array}{l}\text { Scanning } \\
\text { area }\end{array}$ & $y / n / \mathrm{u}$ & $\mathrm{y} / \mathrm{n} / \mathrm{u}$ & & & \\
\hline
\end{tabular}

\begin{tabular}{l|l|l|l|l}
\hline & Receive beep? & Notice beep? & Understand meaning? & Comments / Questions / Behaviors \\
\hline Beep & $y / n / u$ & $y / n / u$ & $y / n / u$ & \\
\hline
\end{tabular}




\begin{tabular}{l|l|l|l|l}
\hline & Notice? & Understand? & $\begin{array}{l}\text { Instructions } \\
\text { seemed to } \\
\text { dominate }\end{array}$ & Comments / Questions / Behaviors \\
\hline $\begin{array}{l}\text { Poster } \\
\text { instructions }\end{array}$ & $y / n / u$ & $y / n / u$ & $y / n / u$ & \\
\hline
\end{tabular}

\section{DIAGRAM LABELING}

\begin{tabular}{l|l|l|l|l}
\hline Notice lights? & Y & N & & What did they say? \\
\hline Any labeling of lights? & Y & N & & \\
\hline Correct labeling? & Y & N & & \\
\hline Notice icons? & & & & \\
\hline Any labeling of icons? & Y & N & & \\
\hline Correct labeling? & Y & N & & \\
\hline
\end{tabular}




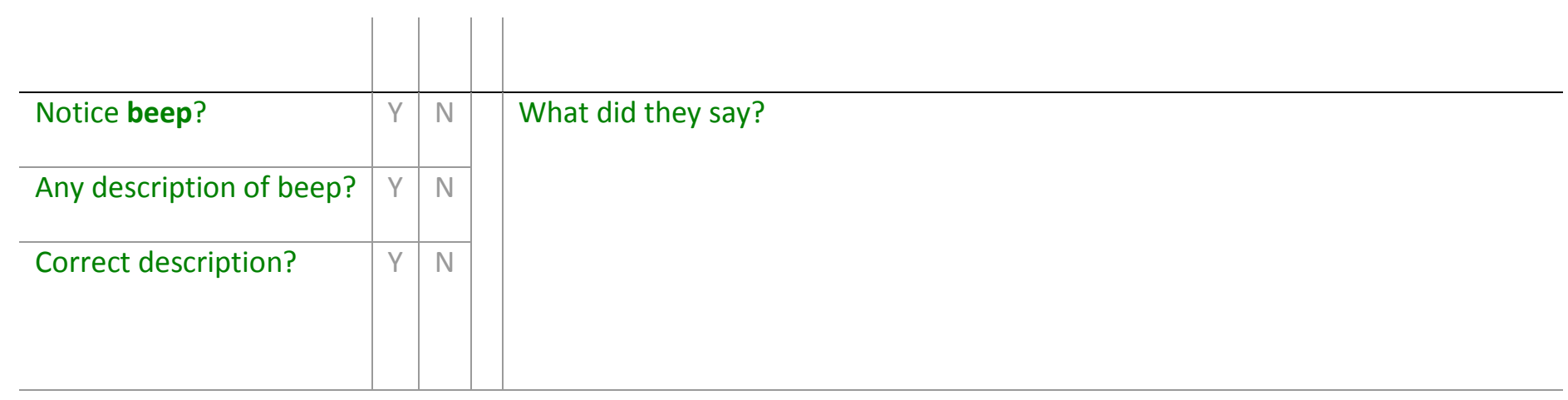

Participant considered instructions to be: Poster / Lights / Icons / Beeps

\section{OVERALL UNDERSTANDING}

\begin{tabular}{l|l|l|l}
\hline $\begin{array}{l}\text { Got it: Could explain to } \\
\text { someone else } \\
\text { how to do it }\end{array}$ & $\begin{array}{l}\text { Muddled through, could not } \\
\text { explain to someone else }\end{array}$ & $\begin{array}{l}\text { Grasped } \\
\text { after scanning }\end{array}$ & Never got it, no data \\
\hline
\end{tabular}


DEBRIEF QUESTIONS

Trip to

Entry place

$\mathrm{MM} / \mathrm{YY}$

Biometrics captured before?

Yes

If yes, what, why: 


\section{APPENDIX C: POST-TASK SURVEY}

Subject \#:

Date:

\section{POST-TASK SURVEY}

1. The instructions provided were effective in helping me complete the fingerprint capture process.

$\begin{array}{lllll}1 & 2 & 3 & 4 & 5\end{array}$

Ineffective $\begin{gathered}\text { Somewhat } \\ \text { effective }\end{gathered} \quad$ Effective $\quad$ Very effective $\quad \begin{gathered}\text { Completely } \\ \text { effective }\end{gathered}$

2. The instructions provided clearly described the fingerprint process.

$\begin{array}{ccccc}1 & \mathbf{2} & \mathbf{3} & \mathbf{4} & \mathbf{5} \\ \text { Unclear } & \text { Somewhat clear } & \text { Clear } & \text { Very clear } & \text { Intuitive }\end{array}$

3. The instructions provided were confusing.

1

Not Confusing

NISTIR 7944
2

Somewhat confusing
3

Confusing

4

Fairly confusing

Very confusing
5

fusing


4. The order of the fingerprint capture was clear.

$\begin{array}{ccccc}1 & \mathbf{2} & \mathbf{3} & \mathbf{4} & \mathbf{5} \\ \text { Unclear } & \text { Somewhat clear } & \text { Clear } & \text { Very clear } & \text { Intuitive }\end{array}$

5. It was clear how to position yourself for the fingerprinting.

$\begin{array}{ccccc}1 & \mathbf{2} & \mathbf{3} & \mathbf{4} & \mathbf{5} \\ \text { Unclear } & \text { Somewhat clear } & \text { Clear } & \text { Very clear } & \text { Intuitive }\end{array}$

6. It was clear when the fingerprint image had been taken.

$\begin{array}{ccccc}\mathbf{1} & \mathbf{2} & \mathbf{3} & \mathbf{4} & \mathbf{5} \\ \text { Unclear } & \text { Somewhat clear } & \text { Clear } & \text { Very clear } & \text { Intuitive }\end{array}$

7. It was clear when the fingerprint process began.

$\begin{array}{ccccc}1 & 2 & 3 & \mathbf{4} & \mathbf{5} \\ \text { Unclear } & \text { Somewhat clear } & \text { Clear } & \text { Very clear } & \text { Intuitive }\end{array}$

8. It was clear when the fingerprint process ended.
1
2
3
4
5 
Clear

Very clear

Intuitive

9. How confident are you that you completed the fingerprint task as intended?

1

Not confident
2

Somewhat confident
3

4

5

Confident Very confident

Certain

10. Would you do anything differently the next time?

11. What was the most confusing part of the process?

\section{Do you have any additional comments on the process?}

NOTE: This survey contains collection of information requirements subject to the Paperwork Reduction Act. Notwithstanding any other provision of the law, no person is required to respond to, nor shall any person be subject to a penalty for failure to comply with, a collection of information subject to the requirements of the Paperwork Reduction Act, unless that collection of information displays a currently valid OMB control number. The estimated response time for this survey is 15 
minutes. The response time includes the time for reviewing instructions, searching existing data sources, gathering and maintaining the data needed, and completing and reviewing the collection of information." OMB Number: 0693-0043 Expiration: 10/31/2012. 